\title{
NUEVAS TECNOLOGÍAS, VIEJOS PROBLEMAS El modelo español de difusión de Internet
}

\author{
YANINA WELP
}

Universidad Pompeu Fabra

\begin{tabular}{ll}
\hline PALABRAS CLAVE ADICIONALES & ADDITIONAL KEYWORDS \\
$\begin{array}{l}\text { Políticas públicas, Fractura digital, Patrones de } \\
\text { expansión, Patrones de acceso. }\end{array}$ & Public Policies, Digital Divide, Diffusioñ Pattern, \\
Access Pattern.
\end{tabular}
expansión, Patrones de acceso.

Access Pattern.

RESUMEN. Este artículo se propone estudiar las variables que explican el nivel de difusión de Internet en España desde una doble perspectiva: "patrones de acceso" (igualitario o desigual) y "patrones de expansión" (masiva o restringida). Controlando la variable desarrollo económico, consideramos que el tipo de interrelación entre intervención pública y privada explica el carácter igualitario o desigual, masivo o restringido, de esta difusión.

\begin{abstract}
This paper takes as a fundamental tasks that of examining the variables that may explain the spread of internet in Spain. We set out to use the following indicators to measure not only the spread of internet but also its nature: "patterns of access to internet" - which can be of the egalitarian or non egalitarian type - and "patterns of diffusion" - which can be massive or restrictive- - We assume that the connection between public and private intervention explains the egalitarian or non egalitarian, massive or restrictive spread of internet in Spain as compare to other case study observed.
\end{abstract}

E-mail: yanina.welp@upf.edu

Revista Internacional de Sociología (RIS)

Tercera Época, No 37, Enero-Abril, 2004, pp. 77-114. 
R I S

REVISTA INTERNACIONAL DE SOCIOLOCIA

No 37, ENERO-ABRIL, 2004

YANINA WELP

\section{INTRODUCCIÓN}

La evidencia empírica señala que altos niveles de difusión de Internet se vinculan con altos niveles de desarrollo económico (OCDE, 2001a; 2002; Hargittai, 1999). Así, los países nórdicos se ubican en los primeros puestos del Information Society Index (ISI)'; Alemania, Austria, Francia o Bélgica presentan niveles moderados de difusión, y los países del sur de Europa se encuentran en los escalafones más bajos. Sin embargo, al observar la difusión de Internet en la educación y en la ciudadanía o el volumen de comercio electrónico y teletrabajo, se encuentran diferencias que quedaban ocultas en la comparación global y que no pueden ser explicadas por la relación entre riqueza y difusión de Internet. Por ejemplo, según datos del Eurobarómetro, mientras Holanda presenta un porcentaje de hogares con conexión a Internet $(65,5 \%)$ levemente superior al de Suecia $(64,2 \%)$ o Dinamarca $(64,5 \%)$, su ratio de ordenadores en red por cada cien estudiantes nô sólo es muy inferior al de estos países - $5,4 \%$ frente a $25 \%$ y $11 \%$ respectivamente-, sino que también es inferior al de España $(6,4 \%)$, que está 36 puntos debajo de Holanda en la cantidad de hogares con conexión a la red.

Asímismo, en el desarrollo del teletrabajo los países del sur de Europa presentan los niveles más bajos de difusión, de Internet, pero junto con Alemania (3,7\%) y Austria (4\%). Y por mencionar un último ejemplo, el porcentaje de hogares conectados Internet en Portugal es bajo (30,8\% frente al $40 \%$ de la media europea) mientras los usuarios alcanzan el $50 \%$ frente al $30 \%$ de Francia o el $36 \%$ de Alemania. Esto manifiesta también la diversidad de formas en que se puede dar la difusión de Internet, ya que los usuarios pueden conectarse desde sus casas o desde el trabajo, y desde centros educativos, puntos de acceso público a Internet o cybercafés.

De lo descrito se deduce que el grado de desarrollo de los países condiciona, pero no determina la difusión de Internet y que esta difusión no sigue un camino lineal y homogéneo, sino que presenta características diferentes en cada país. En este marco nuestro artículo busca dar respuesta a la siguiente pregunta: ¿cuáles son las variables que explican la configuración de la modalidad española de difusión de Internet? La hipótesis central es que la difusión de Internet, controlando la variable desarrollo económico, está condicionada por la interrelación entre la intervención pública y la iniciativa privada. Es decir, que la forma en que se

${ }^{1}$ El Information Society Index (ISI) es un indicador resultante de mediciones en infraestructuras de ordenadores (cantidad de ordenadores en distintas áreas), de difusión de Internet (usuarios por sectores y montos de transacciones electrónicas), infraestructuras de información (líneas telefónicas por hogares, teléfonos móviles per cápita, suscriptores al cable, costos de conexiones, etc.) y sociales (lectores de prensa, estudiantes de nivel secundario y de nivel terciario, libertad de prensa y libertades civiles) (World Paper, 2002). 
Tabla 1.

Indicadores de la Sociedad de la Información y PIB por paises

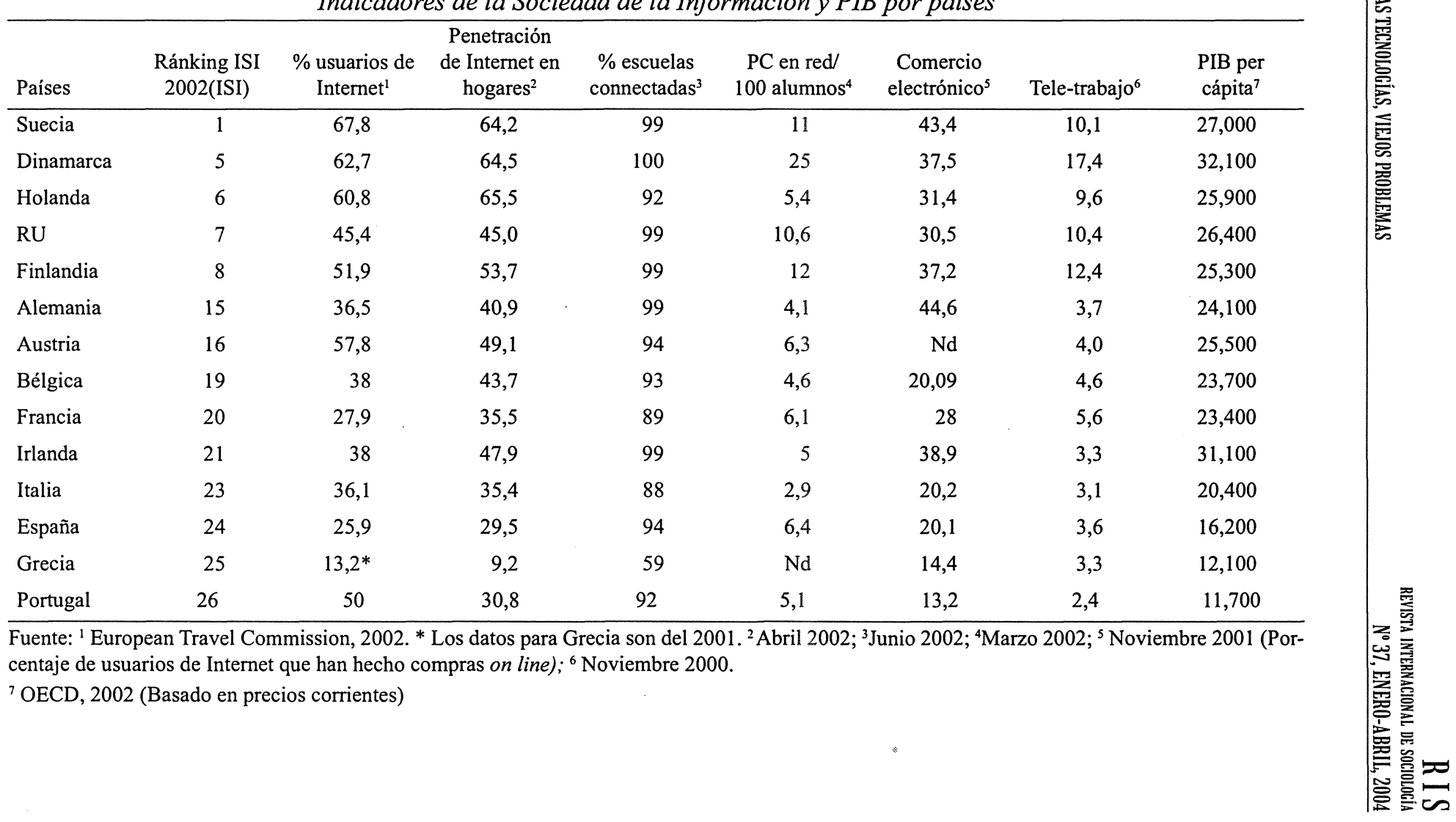


RIS

REVISTA INTERNACIONAL DE SOCIOLOCIA

No 37, ENERO-ABRIL, 2004

YANINA WELP

conjuga la relación entre estas dos variables y el peso relativo de cada una de ellas permite formular distintos modelos de expansión de Internet y, por consiguiente, explicar el modelo español.

Para contestar a la pregunta, proponemos estudiar cuatro áreas en las que Internet está provocando cambios sustanciales: la ciudadanía (usuarios de Internet en general), la educación (ordenadores y conexiones a la red en el sector educativo), la economía (difusión del comercio electrónico y presencia de las empresas en la web) y el trabajo (teletrabajo y uso de Internet por los trabajadores). Las analizaremos a partir de dos patrones de la difusión de Internet: patrón de acceso, que puede ser igualitario o desigual, y patrón de expansión, que puede ser masivo o restringido. Es decir, en nuestro modelo consideraremos la difusión de Internet no sólo por el número de usuarios —expansión masiva o restringida—, sino también por la posibilidad que tengan los ciudadanos de utilizar esta tecnología con independencia de su nivel de renta - acceso igualitario o desigual.

En las siguientes páginas se destaca la importancia de estudiar la difusión de Internet y la de analizar el caso español; se describe y justifica la selección de áreas de estudio y el diseño del modelo de análisis; y, finalmente, se analiza la difusión de esta tecnología en España y se extraen conclusiones.

\section{LA RELEVANCIA DE INTERNET Y EL CASO ESPAÑOL}

El potencial de transformación social, política, económica y cultural de la difusión de Internet convierte a esta tecnología ${ }^{2}$ y sus efectos en un tema clave para la ciencia política y la sociología (Castells, 1997, 2001; Lyon, 1988; Marsden 2000; Dutton, 1996, 1999; Lessig, 2001). Los datos señalan que la difusión, aunque con ritmos y alcances diferentes, está aumentando en todo el mundo. Desde 1995, año

\footnotetext{
${ }^{2}$ Por tecnología se entiende el uso del conocimiento científico para especificar modos de hacer cosas de una manera reproducible (Bell, 1994). Tecnologías de la Información y las Comunicaciones (TIC) son el conjunto convergente de tecnologías de la microelectrónica, la informática (máquinas y software), las telecomunicaciones, la televisión, la radio, la optoelectrónica y la ingeniería genética (Castells, 1997).

${ }^{3}$ Internet surgió en Estados Unidos en 1969, ligada primero a proyectos militares (ARPANET) y más tarde a los centros universitarios de investigación (NSFNET). A partir de la creación de protocolos comunes (TCP/IP) y el World Wide Web (WWW) se dieron dos pasos claves para la apertura de la red a la sociedad y el mundo, que se completaron en 1995 cuando la Fundación Nacional de Ciencias de Estados Unidos (NSF) dejó el control de la red, que pasó a manos privadas. Así se consolidó la estructura básica de lo que hoy conocemos como Internet: una red abierta e interconectada, gestionada por corporaciones privadas, organizaciones sin ánimo de lucro y otras entidades colectivas, que es administrada y utilizada por diversos actores (Abbate, 1999; Hart, Red y Bar, 1992; Malamud, 1993; Drake, 1993; Berners y Fischetti, 1999; Lessig, 2001; Castells, 2001; Werle, 2001).
} 
en que Internet adquiere sus características básicas ${ }^{3}$, los usuarios han pasado de los 16 millones iniciales a 680 millones en septiembre de 2003 y se estima que para finales de 2004 estarán cerca de los 1000 millones (Global Reach, 2003).

Las razones cualitativas justifican aún más su interés. Más allá de las diferencias de enfoques, lo que se ha tendido a denominar Sociedad de la Información (Masuda, 1980; Lyon, 1998) o Sociedad Informacional (Castells, 1997) se describe como una tercera etapa que sucede a la agrícola y a la industrial. Seguimos aquí la línea de investigación iniciada por Castells, que considera que esta nueva estructura social dominante, si bien es un fenómeno mundial, presenta variaciones institucionales, culturales e históricas que son esenciales para comprender el fenómeno en sus manifestaciones concretas. Pese a esta salvedad, que nos sitúa lejos de cualquier determinismo tecnológico, en términos generales podemos decir que la difusión de Internet está cambiando las pautas laborales - modificando las habilidades requeridas para el mercado de trabajo y creando nuevas relaciones de trabajo y nuevos empleos (Machlup, 1987; Freeman, 1996)-, las relaciones Estado-ciudadanía - a través de la modernización administrativa y de la democracia electrónica (Taylor et al. 1996; Cairo Carou, 2002) -, las oportunidades educativas - con la educación no presencial, la educación permanente y el diseño de nuevas modalidades de aprendizaje (Gell and Cochrane, 1996) — y también las transacciones comerciales - creando nuevas formas de negocio (Bacheta, 1998) - , entre otras dimensiones de análisis.

En este contexto, mientras vemos una prolifica actividad gubernamental orientada a impulsar la difusión de Internet, aún son escasos los estudios que busquen entender este proceso y sus consecuencias de una manera sistemática ${ }^{4}$. Para con-

\footnotetext{
${ }^{4}$ Existen obras generales, que se han convertido en clásicos e inscriben la nueva etapa en el marco de un cambio de paradigma y/o en la emergencia de la sociedad de la información. Entre los pioneros, Daniel Bell (1973) describía el advenimiento de la "sociedad postindustrial" centrándose en los cambios en el modo de producción: predominio del sector servicios sobre el industrial, del empleo en los sectores profesionales y técnicos y del conocimiento como fuente de la economía. Alain Touraine (1969) caracterizaba esta nueva época como "sociedad programada", poniendo énfasis en la transformación que se origina dentro del sistema de dominación. Pocos años después, Yoneji Masuda comienza a hablar de "sociedad de la información" (1981), observando especialmente el valor del conocimiento y de la planificación basada en nuevas tecnologías. Un trabajo posterior desarrollado en esta línea es la obra de Castells, La era de la Información (1997). En las últimas dos décadas, los debates enfrentaron visiones extremas que han simplificado y distorsionado la comprensión del proceso de cambio real (Miles, 1996; Lyon, 1988). Algunos de los ejes de estas polémicas fueron los siguientes: las TIC como herramientas para reinventar los gobiernos y los negocios (Hammer and Champy, 1994); las nuevas networks y servicios de Internet como potenciales creadoras de una sociedad virtual que socavaría la cohesión de las comunidades reales (Slouka, 1996); las TIC como promotoras del desempleo masivo (Wienner, 1989) o del fin del trabajo (Rifkin, 1995); o las nuevas tecnologías como instrumentos para alcanzar el progreso y bienestar per se (Negroponte, 1995, Toffler, 1990), sólo por mencionar a algunos de los autores que han trabajado el tema. En la
} 
RIS

REVISTA INTERNACIONAL DE SOCIOLOGIA

No 37, ENERO-ABRIL, 2004

YANINA WELP

tribuir a solventar esta carencia nos proponemos aquí entender las dimensiones de la difusión de Internet como resultado de la configuración institucional en que este proceso se desarrolla, lo que le otorga modalidades específicas estrechamente vinculadas con las características sociopolíticas del territorio en que se materializa.

¿Qué aporta estudiar España? El caso español presenta particularidades relevantes para poner a prueba el enfoque neoinstitucionalista, ya que vemos, junto a características institucionales "propias", la influencia de las directivas de la Unión Europea (UE). Es decir, podemos analizar la forma en que se conjugan las tendencias históricas del país con las presiones externas y estímulos a la convergencia (Thatcher, 2000). Por otra parte, al tratarse de un nuevo área de intervención para las políticas públicas, permite analizar la forma en que los contextos institucionales se organizan cuando no hay experiencia previa. Esta conjunción de elementos permite aislar y analizar la intervención de las variables institucionales en el desarrollo de las políticas públicas y sus consecuencias, tal como diversos autores han propuesto para otras áreas de políticas en diversos países (Pierson, 1993, 2000; Collier y Collier, 2002; Immergut, 1992; Thatcher, 2000).

Como características generales - antes de profundizar en el análisis - podemos destacar que en España, al igual que ocurre en otros ámbitos de la intervención pública, en el fomento de Internet intervienen tanto la Administración General del Estado como las Comunidades Autónomas (CC.AA). Las características de estas intervenciones hacen que a menudo el resultado de las políticas se traduzca en la diferenciación regional y en problemas de coordinación entre ambos niveles de gobierno (eEspaña, 2002; Jordana et al., 2003a). Por otra parte, al observar las planificaciones estratégicas diseñadas por la Administración central, encontramos que la intervención pública española orientada a la difusión de las nuevas tecnologías e Internet fue tardía. El primer plan de este tipo (el Info XXI) fue lanzado a finales de 1999 y entró en vigencia con posterioridad a esa fecha, mientras Finlandia, Holanda o Bélgica presentaron sus primeras planificaciones en 1994 y Alemania o Suecia en 1996 (Jordana et al., 2003b). Esto no implica que no hubiera un interés previo en este área, en la que se habían desarrollado algunas acciones sectoriales especialmente orientadas a promover la administración electrónica ${ }^{5}$. El Info XXI

actualidad una incipiente bibliografía explica las causas de la difusión de Internet en el contexto internacional (Milner, 2002); define modelos de difusión en estudios de caso o comparaciones entre países (Castells e Himanen, 2002; Guillén y Suárez, 2001; Wolcott et al., 2001 y 2003); aborda los efectos de Internet sobre áreas como la educación, el gobierno, el comercio, la brecha digital o el trabajo (Dutton, 1996; Norris, 2000; Gell y Cochrane, 1996; Miles, 1996; Bradford de Long, 1998; Gibbs, et al., 2002; Hargittai, 1999), o estudia el efecto de las políticas públicas en la difusión de Internet (Jordana et al., 2003a).

${ }^{5}$ Uno de los proyectos destacados fue el programa Pista (Promoción e Identificación de Servicios Emergentes de Telecomunicaciones Avanzadas), que más tarde se incorporó al Plan estratégico Info XXI. Entre sus líneas de intervención, el proyecto Ventanilla Única buscaba realizar un sistema intercomunicado de registros en el que participaran los distintos niveles de las administraciones españolas. 
se vinculó a las consignas propuestas por la Comisión Europea en el Plan eEurope, que promovía alcanzar unos objetivos comunes a partir de iniciativas que cada Estado debía desarrollar con autonomía.

Sin embargo, pese al mencionado plan y a la intervención activa de algunas Comunidades Autónomas que, como Murcia, Extremadura, Valencia (desarrolladas en el marco de la UE) o Cataluña, iniciaron su intervención con anterioridad al lanzamiento del Info XXI, los datos indican que España sigue a la zaga en la difusión de Internet. Por ejemplo, según el Estudio General de Medios (EGM, 2003), sólo un 27,4\% de los españoles utilizó Internet durante el mes en que se realizó la encuesta, aunque los resultados muestran también que se comienza a superar el estancamiento ${ }^{6}$. Si bien en otros países de la Unión Europea ha ocurrido una ralentización en el crecimiento de los usuarios, mientras la media europea de hogares conectados es del $40 \%$, la media española es del 29\% (Eurobarómetro, 2002). Algo semejante ocurre en otras áreas, como el teletrabajo o el comercio electrónico, en los que España no muestra buenos niveles de difusión.

\section{UNA PROPUESTA DE ANÁLISIS}

Este sección se desarrolla en tres apartados. En primer lugar haremos algunas consideraciones sobre las fuentes estadísticas, que en la difusión de Internet se caracterizan por la heterogeneidad y la divergencia. En segundo lugar, desarrollaremos el marco teórico, una serie de conceptos que aporta el neoinstitucionalismo y que nos permiten aproximarnos a la comprensión de la difusión de Internet en un caso concreto. Por último, describiremos nuestra propuesta analítica que, a partir de una selección de indicadores (que no pretende ser exhaustiva, sino hacer posible una buena aproximación a sus principales áreas), permite ubicar el modelo español.

\section{Las estadísticas de Internet}

Los indicadores que miden el desarrollo de la Sociedad de la Información (SI) son muchos ${ }^{7}$. Como anticipábamos al comenzar el artículo, uno de los más consolidados es el Information Society Index (ISI) publicado en World Paper (2002).

\footnotetext{
${ }^{6}$ La encuesta que se realizó entre abril y mayo muestra un leve avance: para febrero de 2003 el porcentaje era del $25 \%$ mientras entre abril y noviembre de 2002 se había mantenido estancado en el $22 \%$ (Publicado en AIMC, $2^{\circ}$ ola 2003, abril/mayo).

${ }^{7}$ Por ejemplo, el indicador básico de la OCDE (2001) centra sus estudios y actividades sobre la brecha digital, que es la cantidad de líneas telefónicas por usuarios, ya que esto permite disponer de la opción de acceder a la red. Dentro de la Unión Europea también se ha desarrollado un ránking de 24 indicadores; la mayoría de sus componentes se refieren a la difusión de Internet en diversos
} 
RIS

REVISTA INTERNACIONAL DE SOCIOLOCIA

№ 37, ENERO-ABRIL, 2004

YANINA WELP

El último indicador del ISI incluye consideraciones sobre la influencia directa de la tecnología, que asocian la Sociedad de la Información con algunos parámetros básicos de las democracias occidentales (ver nota al pie $n^{\circ} 1$ ). Este hecho dificulta la comprensión de aspectos específicos en tanto puede haber casos de países con altos niveles de difusión que no se vean reflejados con claridad en este ránking por tener sistemas políticos autoritarios (este es el caso de Singapur). Ya que el objetivo de esta investigación es comprender las variables que intervienen en la difusión de Internet, la variable dependiente sólo debe considerar la difusión de Internet, luego analizar las variables explicativas.

Pero aún con esta salvedad continúan las dificultades. La proliferación de fuentes de datos y la divergencia que encontramos entre los mismos sugieren que los análisis pueden ser confusos, por lo que conviene analizar el origen de estas diferencias, problema que se acentúa por la velocidad de crecimiento que se observa en los primeros años de difusión de la tecnología, en que las tasas de expansión suelen ser exponenciales (ver un ejemplo en la tabla 3). Las diferencias en los indicadores provienen tanto de la dificultad como de la falta de consenso para establecer criterios de recopilación de datos. Por ejemplo, medir las dimensiones del comercio electrónico es difícil por las siguientes razones: el número de empresas que pueden participar en una transacción puede ser muy elevado y la importancia de cada una es variable; muchos de los productos comercializados tiene un valor añadido difícil de cuantificar; el carácter transnacional de las transacciones provoca que una misma transacción se pueda computar más de una vez (Bacchetta, 1998). Además, algunas fuentes consideran que una persona es comprador on line si ha comprado "alguna vez en su vida", mientras otras estipulan que debe haber comprado en los tres meses previos a la encuesta. A la hora de evaluar quiénes son usuarios ocurre algo semejante, y algunas fuentes diferencian entre usuarios cotidianos y usuarios ocasionales. Por citar un último caso, con las fuentes que miden el teletrabajo ocurre lo mismo, no existiendo una definición jurídica que permita comparar realidades nacionales (CIDEC, 2003; Perez de los Cobos y Thibault Aranda, 2001). Las principales divergencias giran en torno a la delimitación espacial concreta del teletrabajo (en el domicilio, en un telecentro, con alternancia entre la oficina y el hogar); a la delimitación temporal del teletrabajo realizado fuera de la empresa (horas semanales, días, etc); a la

ámbitos (usuarios en general, empresas conectadas, Internet en escuelas, porcentaje de contenidos en la web por países, calidad de conexión, etc.) y los que no están directamente vinculados a la red se refieren a la cantidad de graduados con formación básica en TIC y número de plazas de graduados en TIC en la enseñanza superior (UE, 2000). A diferencia del ISI, estos indicadores se centran estrictamente en datos de infraestructura y difusión de Internet. Por último, numerosas consultoras miden el desarrollo de Internet en los negocios (Forrester, ActiMedia o Gartner Group, sólo por mencionar algunas. Ver listado de links en la bibliografia). 
intensidad del empleo en TIC; a la cuantificación como teletrabajadores tanto de los asalariados como de los autónomos o solamente de los primeros; y a la inclusión o no de los directivos en la categoría de teletrabajadores ${ }^{8}$ (CIDEC, 2003).

En esta investigación hemos recurrido a la misma fuente de datos a la hora de comparar entre países o Comunidades Autónomas, con lo que evitamos estas diferencias de criterio que considerábamos antes. Por otra parte, hemos utilizado datos de fuentes con larga experiencia en la recopilación de estadísticas (Unión Europea -Eurobarómetro o European Travel Comission-, Internacional Telecommunications Union y fuentes públicas españolas como la AIMC, CMT y EGM). En conclusión, los datos agregados tienen la validez suficiente para el análisis, especialmente por el carácter exploratorio del mismo (dentro del que, en cierta forma, se constituyen como objeto de estudio).

\section{El neoinstitucionalismo}

Nuestro marco analítico se inscribe en la corriente neoinstitucionalista, en particular en el enfoque del institucionalismo histórico $0^{9}$. Consideramos que las instituciones son claves en la creación de reglas (formales e informales) e incentivos para el comportamiento de los individuos (Peters, 2003). Brevemente, describiremos algunas nociones relevantes para nuestro tema de estudio.

La primera noción es la de path dependence, definida como la influencia de determinada configuración institucional sobre los resultados de las políticas públicas. El concepto se refiere al establecimiento de particulares cursos de acción que una vez introducidos, pueden ser muy dificiles de modificar (Powell y DiMaggio, 1991). La segunda noción es la de critical junctures (coyunturas críticas), definidas como momentos de transición en los que se establecen direcciones de actuación que pueden organizar las políticas predominantes de los años posteriores a dichas coyunturas, lo que agrega una visión dinámica a la path dependence (Collier y

\footnotetext{
${ }^{8}$ A modo de ejemplo, señalamos que Huws (1993) considera teletrabajadores a los que trabajan un mínimo del $50 \%$ del tiempo en su propio domicilio o en un centro satélite; trabajan para una empresa un mínimo de 10 días o el equivalente en horas durante las cuatro últimas semanas; son parte de la empresa o trabajan de manera independiente, pero existiendo un contrato directo con la empresa; y utilizan dispositivos de telecomunicaciones y de procesamiento de datos durante la realización a distancia de su actividad laboral.

${ }^{9}$ Frente al primer institucionalismo, basado en las reglas formales que estructuran el comportamiento de los agentes, el neoinstitucionalismo presenta una variada gama de explicaciones: algunas corrientes continúan basándose en las normas, aunque incluyendo también procesos informales (March y Olsen); otras han combinado el poder de las instituciones con las teorías de la elección racional (Scharpf), o con la historia y, más concretamente, con las consecuencias posteriores de las decisiones tomadas en el pasado durante el proceso de creacion de instituciones (Skocpol) (para más detalles ver Peters, 2003)
} 
RIS

REVISTA INTERNACIONAL DE SOCIOLOCIA

№ 37, ENER0-ABRIL, 2004

YANINA WELP

Collier, 2002). Esto permite analizar las políticas públicas como causa y no sólo como resultado de la demanda, es decir, como creadoras o promotoras de grupos de interés que refuerzan los efectos de las políticas y demandan acciones frente al Estado (Pierson, 1993 y 2000). La tercera noción es la de isomorfismo institucional, que explica la tendencia a adoptar fórmulas institucionales aceptadas y consolidadas en su entorno de referencia más allá de su efectividad y eficiencia. Finalmente, se utiliza la noción de decoupling, para mostrar el desajuste entre las instituciones formales y su funcionamiento efectivo, desajuste que ocurre como respuesta a la falta de eficacia de las instituciones o cuando se produce un conflicto entre diversos marcos institucionales con pautas que no se ajustan entre sí (Meyer y Rowan, 1991).

Tal como afirmábamos, el estudio del caso español a partir de las teorías noeinstitucionales es relevante porque permite evaluar la forma en que las características institucionales se conjugan con los estímulos a la convergencia promovidos desde el ámbito europeo. El que se trate de un nuevo área para las políticas públicas agrega interés al estudio, aunque también crea limitaciones, ya que la novedad de este campo de investigación ubica a este estudio en una fase exploratoria, y genera la necesidad de crear instrumentos de análisis. En este sentido, el artículo busca tanto analizar el caso español como plantear una aproximación metodológica a los estudios de la difusión de Internet.

\section{Modelo de análisis}

Nuestra variable dependiente es el nivel de penetración de Internet, medida en cuatro áreas: ciudadanía en general, educación, economía y empresa, y trabajo, cuya descripción será el objeto de este apartado. Posteriormente, y a partir de una selección de indicadores básicos que permiten simplificar el análisis y profundizar en la consideración de los mismos, definiremos nuestra propuesta analítica.

\section{El acceso de la ciudadanía a Internet}

La digital divide es la brecha que separa a los que tienen acceso a las nuevas tecnologías de los que no ${ }^{10}$ (OECD 2001a). Algunos estudios consideran que la fractura digital o brecha es un reflejo de otras desigualdades (Compaine, 2001),

\footnotetext{
${ }^{10}$ Esta distancia se puede medir en la relación entre países, entre ciudadanos y/o regiones de un mismo Estado, entre sectores del planeta, etc. Las desigualdades medidas son numerosas: por ejemplo, en la producción y el consumo de contenidos entre países, los EEUU concentran el $75 \%$ de los servidores conectados a la red, pero sólo el 35\% de los usuarios (ITU, 2001); en el interior de los países hay una brecha entre zonas avanzadas y zonas más pobres - mientras en Madrid el porcentaje de usuarios alcanza el 32,6\%, en Castilla La Mancha es de 16,8\% (AIMC 2003, abril/mayo)-; y también es pronunciada la diferencia en los idiomas que predominan en la red -el $35,2 \%$ de la
} 
pero otros afirman que es una nueva forma de desigualdad que multiplica la distancia entre quienes acceden y quienes no (Jordana, 2001; Norris, 2000). Si se trata de lo primero, sólo habrá que esperar a que el uso de Internet se generalice, como ocurrió con otras tecnologías ${ }^{11}$. Sin embargo, quienes piensan que no se trata sólo de un problema de expansión de la nueva tecnología, promueven que se convierta en un tema que esté en la agenda para el desarrollo de los países y la calidad de vida de los ciudadanos (OCDE, 2001a; Proenza, 2001). Esta propuesta se basa principalmente en la consideración de que la población más susceptible de quedar fuera del acceso a Internet es la menos educada, la más pobre y la más discriminada, con lo que tendería a ampliarse la desigualdad entre individuos, regiones y países. Por ejemplo, la persistencia de un amplio sector de trabajadores no alfabetizados digitalmente puede conducir a una mayor segmentación de los empleos (entre los que requieren gestionar información digital y los que no) (Jordana, 2001) y también puede incrementar la brecha entre los países ricoss y los países pobres (CEPAL, 2003). Nuestros indicadores para el análisis de este area serán el porcentaje de usuarios en general y el de usuarios en centros de acceso público a Internet, vinculados ambos al patrón de acceso, en tanto exista o no la posibilidad de ser usuario de Internet con independencia del poder adquisitivo. El porcentaje de hogares conectados permite, por su parte, observar el patrón de expansión, vinculado con la renta.

\section{Las TIC en la educación}

Tres dimensiones se vinculan con los efectos de Internet en el área de la educación: la creación de nuevas áreas de conocimiento (y profesiones y actividades); el impulso a la educación continua, y los cambios en los modelos de aprendizaje. La primera de estas dimensiones - la creación de nuevas areas educativas - no se relaciona exclusivamente con Internet, ya que puede verse como consecuencia del surgimiento de sectores productivos, la transformación de otros debido a la puesta en marcha de innovadores patrones de organización y la posible desaparición de puestos de trabajo como subproducto de la revolución tecnológica (Freeman, 1996). En segundo lugar, existe, en todo caso, una tendencia a considerar relevante la formación continua a lo largo de

\footnotetext{
información está en inglés y sólo el 8,1\% en español pese a que la cantidad de hispanohablantes es muy superior (Global Reach, 2003).

${ }^{11}$ Sin embargo, la tendencia señala una ralentización de la expansión de Internet incluso en los países en que el crecimiento ha sido elevado, como Suecia o Estados Unidos, donde un tercio de la población continúa al margen de este proceso (Datos de ITU, 2002). Por otra parte, la extrapolación de distintas pautas de expansión muestra escenarios diferentes: en los países desarrollados el teléfono dejó a amplios sectores de la población al margen durante décadas, mientras la televisión se extendió muy rápidamente por todos los sectores sociales (Jordana, 2001).
} 
toda la vida y la flexibilización de las opciones cognoscitivas (Masuda, 1981; Gell y Cochrane, 1996) En tercer lugar, y como proceso paralelo, se producen cambios en el interior del sistema educativo por la incorporación de Internet al aprendizaje, que plantean necesidades de infraestructura y de formación de los profesores (CE, 2000). Nuestro indicador para el análisis será el número de usuarios de Internet en centros educativos, vinculado con los patrones de acceso, ya que la difusión de Internet en este sector - considerando tanto la intervención pública como la privada - es una herramienta contra la brecha digital, especialmente para los sectores con menores recursos, donde los niños podrían adquirir en la educación pública las herramientas básicas para afrontar los nuevos retos de las tecnologías.

\section{El comercio electrónico}

El comercio electrónico, es una nueva forma de negocio, vinculada a la "nueva economía"12. Según la definición de la OCDE (1999), el comercio electrónico se refiere a todo tipo de transacciones relacionadas con actividades comerciales (entre organizaciones y entre individuos) y basadas en el procesamiento y la transmisión de datos digitalizados (de texto, de sonido e imágenes) Los indicadores a utilizar serán el porcentaje de usuarios de Internet que compran on line y el porcentaje de Pymes con presencia web. Este segundo indicador, si bien es parcial, ya que no implica que las empresas compren y vendan on line y sólo se orienta a un tipo de empresas, es útil para observar el nivel de penetración de Internet en la economía (en un sector cuantitativamente muy importante dentro del tejido económico español); por otra parte, la presencia web es el primer paso hacia el comercio electrónico. El desarrollo del comercio electrónico está condicionado por la renta y por la oferta de servicios diferenciales, por lo que se vincula con el sector privado, y por lo tanto, con los patrones de expansión.

\section{El teletrabajo y las TIC en el empleo}

Aunque el trabajo a distancia existía con anterioridad, Internet crea las condiciones para estimular que este tipo de empleo se extienda a nuevos sectores laborales y

\footnotetext{
${ }^{12}$ Alvin Tofler (1990) fue uno de los primeros en hablar de la "nueva economía", caracterizándola por el predominio del sector servicios por encima de los sectores industrial y agrícola. También surgen nuevos productos, estrategias de producción y distribución, métodos de organización empresarial, modalidades de consumo e inversión y pautas laborales relacionadas con las nuevas tecnologías. El presupuesto que subyace a la transformación es que las inversiones en tecnologías de la información e inversiones afines generan mayores tasas de crecimiento de la productividad (Castells, 1997).
} 
adquiera características propias ${ }^{13}$. La Comisión Europea ha propuesto una definición amplia del teletrabajo como un método de organizar el trabajo mediante el cual una proporción considerable del tiempo dedicado a la actividad laboral se produce a distancia de las oficinas de la empresa, y en el que dicha actividad se realiza con el uso de tecnologías de la información y de tecnologías de transmisión de datos, en modo particular con Internet. Esta definición incluye actividades como el teletrabajo en el hogar y la alternancia entre trabajo en la oficina, el teletrabajo móvil y el trabajo en locales de telecentros (AET, 2001). Este fenómeno laboral se analizará aquí a través de dos indicadores: el porcentaje de teletrabajadores (sobre el empleo total) y el porcentaje de trabajadores que acceden a Internet en el empleo. Ambos se vinculan con nuestro patrón de expansión por su especial dependencia del impulso del sector privado.

Cabe destacar que en todas las áreas mencionadas el Estado desempeña un papel relevante como promotor, regulador y encargado de crear un marco jurídico que estimule o restrinja estas nuevas modalidades de interacción (Samuelson, 2000; Marsden, 2000). En el cuadro 1 se observan los indicadores enumerados antes y que pueden ser reagrupados según correspondan al patrón de acceso -igualitario o desigual - o al de expansión - masiva o restringida - según se detalla en el cuadro 2.

Cuadro 1.

Selección de indicadores de la difusión de Internet

\begin{tabular}{|l|l|}
\hline Áreas & \multicolumn{1}{|c|}{ Indicadores de penetración de Internet } \\
\hline Ciudadanía en general & $\begin{array}{l}\text { Porcentaje de usuarios de internet (total) } \\
\text { Porcentaje de usuarios de puntos de acceso público a Internet } \\
\text { Porcentaje de hogares conectados }\end{array}$ \\
\hline Educación & Porcentaje de usuarios de Internet en centros educativos \\
\hline Economía y empresa & $\begin{array}{l}\text { Porcentaje de usuarios que compran online } \\
\text { Porcentaje de Pymes con presencia web }\end{array}$ \\
\hline Trabajo & $\begin{array}{l}\text { Porcentaje de la fuerza de trabajo que hace uso del teletrabajo } \\
\text { Porcentaje de trabajadores que usan Internet }\end{array}$ \\
\hline
\end{tabular}

\footnotetext{
${ }^{13}$ En el marco de la Unión Europea, el teletrabajo es visto como una estrategia clara de mejora de la productividad y de la calidad de vida a partir del cambio tecnológico; como una posibilidad de mejorar las perspectivas laborales de grupos con baja tasa de empleo, especialmente atractivo y accesible para comunidades locales; y como generador de mayor flexibilidad en tiempo y lugar de trabajo (AET, 2001).
} 
Cuadro 2.

Indicadores de los patrones de acceso y expansión

\begin{tabular}{|c|c|}
\hline $\begin{array}{l}\text { Indicadores del patrón de acceso: } \\
\text { Igualitario - Desigual }\end{array}$ & $\begin{array}{l}\text { Indicadores del patrón de expansión: } \\
\text { Masivo - Restringido }\end{array}$ \\
\hline$\%$ de usuarios de Internet (total) & $\%$ de hogares conectados a Internet \\
\hline$\%$ de usuarios en puntos de acceso público a & $\%$ de usuarios que compran on line \\
\hline Internet & $\%$ de Pymes con presencia web \\
\hline $\begin{array}{l}\% \text { de usuarios de Internet en centros } \\
\text { educativos }\end{array}$ & $\begin{array}{l}\% \text { de la fuerza de trabajo que hace uso del } \\
\text { teletrabajo }\end{array}$ \\
\hline
\end{tabular}

En ausencia de una eficiente y activa política de promoción y difusión, el acceso a Internet será desigual y quedará condicionado por el nivel de renta. En esta línea argumental, vinculamos las políticas de impulso al desarrollo de Internet con las nociones de servicio universal ${ }^{14}$, entendido en términos restringidos como la garantía de universalidad en el acceso, tarea en la que el Estado desempeña hoy un rol relevante y no sólo en los países desarrollados ${ }^{15}$.

\section{Las variables explicativas: desarrollo económico e intervención pública}

Numerosos estudios han mostrado la influencia que tiene la riqueza de los países en la difusión de Internet. Aun así, esta variable no es suficiente para entender las diferencias entre países con semejantes niveles de desarrollo, ni explica los factores que intervienen para que países menos desarrollados muestren mejores resultados en algunas áreas que algunos países más ricos (Guillén y Suárez, 2001; Milner, 2003; Castells e Himanen, 2002; Gibbs et al., 2003). Así, hay que considerar indicadores como el PIB per cápita o el nivel de infraestructuras (desarrollo de la banda ancha, conexiones telefónicas, cantidad de ordenadores por habitante) para evaluar el punto de partida sobre el que se inscribe la expansión de Internet y el

\footnotetext{
${ }^{14}$ La noción de "servicio universal" surge a principios del siglo XX en Estados Unidos, en el marco de la defensa del monopolio natural en los servicios de telefonía. Tras la liberalización de las telecomunicaciones en la mayor parte de los países del mundo - en los años ochenta y noventa-, la noción es reformulada para aceptar la participación privada y la competencia; lo que se mantiene es el principio de universalidad entendido como el derecho de los ciudadanos a acceder a determinadas tecnologías con independencia de su nivel de renta y del lugar en que se habite (Macià, 1999).

${ }^{15}$ Por ejemplo, incluso en países en vías de desarrollo, se considera la importancia de promover el acceso a Internet. Así, en la última década, en Trinidad y Tobago, Dominica, Jamaica y Granada se han introducido cambios constitucionales para que el derecho a la libertad de expresión y de palabra abarque el derecho al acceso a la infraestructura (medios) para ejercer dicha libertad (CEPAL, 2003).
} 
potencial de creación de oferta y demanda de productos ligados a esta tecnología. Asimismo, debe tenerse en cuenta la importancia de la intervención pública y la participación de la sociedad civil a través de organizaciones específicas de usuarios de Internet, cámaras de comercio, asociaciones de trabajo, etc. que orienten sus actividades a la promoción de Internet.

Incluimos en este análisis las políticas públicas de regulación, promoción y difusión. Dentro de las políticas de regulación circunscribimos las que tratan de definir las reglas del juego para los actores económicos y sociales, como las reglas de competencia, las condiciones de creación de empresas, la protección de datos, la seguridad en las transacciones, etc.. Entre las políticas de promoción destacan las de potenciar la oferta de servicios a través de estímulos fiscales a la creación de empresas, la formación de técnicos o el impulso a emprendedores. Finalmente, respecto a las políticas de difusión, deben orientarse a potenciar la demanda de nuevos servicios y utilidades para que se produzca la masa ${ }_{\text {crítica }}$ capaz de estimular el círculo virtuoso de aprendizaje y crecimiento (Jordana et al., 2003b). También habría que considerar la participación social, especialmente a través de la creación de instituciones que representen y reúnan las demandas en el área de que se trate.

\section{Hipótesis}

Si se controla la variable "desarrollo económico", la penetración de Internet está condicionada por la interrelación entre la intervención pública y la iniciativa privada. Conocer el modo en que estas variables afectan a la penetración de Internet y su importancia relativa en cada caso permitirá definir modelos que provocan distintos resultados. En este marco de análisis, las hipótesis planteadas son las siguientes:

1) La combinación de una intervención pública activa en contextos de bajo desarrollo económico y baja intervención privada causa una reducida brecha digital (vinculada a la posibilidad de acceder a Internet con independencia del nivel de renta) y menor desarrollo del teletrabajo y el comercio electrónico (vinculados especialmente al impulso del sector privado).

2) Un alto desarrollo económico, combinado con alta intervención privada y reducida intervención pública, producirá una mayor expansión del comercio electrónico y hará que se incrementen o se consoliden las desigualdades preexistentes.

3) En un modelo mixto, se originará un círculo virtuoso entre el desarrollo económico, la intervención privada y la intervención pública orientada a promover la igualdad en el acceso, dando lugar a bajos niveles en la brecha digital y a un desarrollo equilibrado en la difusión de Internet. En este caso, se espera que exista una masa crítica capaz de retroalimentar el proceso, demandando, por ejemplo, servicios públicos on line como una oferta de productos vinculados al sector privado. 
RIS

REVISTA INTERNACIONAL DE SOCIOLOCIA

№ 37, ENERO-ABRIL, 2004

YANINA WELP

4) Un cuarto modelo combinaría una baja intervención estatal con bajos niveles de desarrollo e intervención privada, provocando tanto una pronunciada brecha digital, como un bajo desarrollo del comercio electrónico y del teletrabajo, y una tendencia al estancamiento mientras no existan estímulos para impulsar el proceso de crecimiento.

Las hipótesis anticipan una tipología que permitiría agrupar a las unidades de análisis ${ }^{16}$ en alguno de los siguientes tipos:

Cuadro 3.

Modelos de difusión de Internet según patrones de acceso y expansión

\begin{tabular}{|l|c|c|}
\hline \multirow{2}{*}{ Patrón de acceso } & \multicolumn{2}{|c|}{ Patrón de expansión } \\
\cline { 2 - 3 } & Masivo & Restringido \\
\hline \multirow{2}{*}{ Igualitario } & Igualitario-Masivo & $\begin{array}{c}\text { Igualitario-Restringido } \\
\text { (1) }\end{array}$ \\
\hline \multirow{2}{*}{ Desigual } & Desigual-Masivo & $\begin{array}{c}\text { Desigual-Restringido } \\
(4)\end{array}$ \\
\hline
\end{tabular}

En resumen, el marco analítico que proponemos incluye, al menos, las siguientes tres variables: desarrollo económico (PIB per cápita, teléfonos, gastos en $\mathrm{I}+\mathrm{D}$, etc); niveles de gobierno que intervienen (nivel europeo, nivel central, nivel autónomico); y tipo de intervención pública gubernamental (instituciones que intervienen, tipo de políticas, etc.). No obstante, y dado el carácter exploratorio de la presente investigación, consideraremos también el aporte de otras variables, como la participación de asociaciones y el posible efecto de los contextos institucionales sobre la confianza e interés de los usuarios reales y potenciales de Internet en España.

\footnotetext{
${ }^{16}$ Para poder ubicar distintos países en los cuadrantes deberíamos realizar un estudio que permita compararlos en función de las mismas variables. A modo de ejemplo del modelo podríamos sugerir que, siguiendo investigaciones previas y partiendo de la idea de que el desarrollo económico condiciona el desarrollo de Internet (con lo que el grado de igualdad-desigualdad se vuelve un concepto relativo al nivel de riqueza), podríamos ubicar a Finlandia en el cuadrante 1 y a Estados Unidos en el 3 (basado en Castells e Himanem, 2002). Luego, entendiendo esto en términos relativos, en América Latina podríamos considerar que Perú tiende a ubicarse en el cuadrante 2 - con una intensa política de creación de centros públicos y un alto índice de usuarios por ordenador-, mientras Argentina quedaría en el 4, dado que la posibilidad de ser usuario frente a no serlo está especialmente condicionada por el nivel de renta (basado en CEPAL, 2003).
} 
Tabla 2.

Indicadores de desarrollo

\begin{tabular}{lccccc}
\hline & $\begin{array}{c}\text { Teléfonos } \\
\text { por cada 100 } \\
\text { Habitantes }\end{array}$ & $\begin{array}{c}\text { Ordenadores } \\
\text { personales } \\
\text { por cada } 100 \\
\text { Hab. }^{2}\end{array}$ & $\begin{array}{c}\text { \% Suscripto- } \\
\text { res de banda } \\
\text { ancha cada } \\
100 \text { Hab }^{3} .\end{array}$ & $\begin{array}{c}\text { Teléfonos } \\
\text { móviles cada } \\
100 \text { Hab. }^{4}\end{array}$ & $\begin{array}{c}\text { PIB per } \\
\text { cápita }^{5}\end{array}$ \\
\hline Suecia & 72,02 & 56,12 & 9,16 & 88,89 & 27,000 \\
Dinamarca & 69,58 & 57,68 & 11,11 & 83,32 & 32,100 \\
Holanda & $62,11^{*}$ & 42,84 & 9,20 & 74,47 & 25,900 \\
RU & $58,74^{*}$ & 36,62 & 3,63 & 84,07 & 26,400 \\
Finlandia & 54,73 & 44,17 & 6,61 & 86,74 & 25,300 \\
Alemania & 65,04 & 43,49 & 4,84 & 72,75 & 24,100 \\
Austria & $46,81^{*}$ & 33,54 & 6,98 & 76,82 & 25,500 \\
Bélgica & 49,61 & 24,16 & 10,34 & 78,56 & 23,700 \\
Francia & 56,89 & 34,71 & 4,13 & 64,70 & 23,400 \\
Irlanda & $48,45^{*}$ & 39,07 & 0,41 & 76,32 & 31,100 \\
Italia & 48,62 & 19,48 & 2,84 & 93,87 & 20,400 \\
España & 45,98 & 16,82 & 4,24 & 82,42 & 16,200 \\
Grecia & $52,92^{*}$ & 8,12 & 0,02 & 84,54 & 12,100 \\
Portugal & 41,90 & 11,74 & 3,72 & 82,52 & 11,700 \\
\hline & & & & & \\
\hline
\end{tabular}

Fuente: ${ }^{~}$ ITU $2002 *$ datos del 2001, ${ }^{2}$ ITU 2001, ${ }^{3}$ OCDE 2003, ${ }^{4}$ ITU 2002, ${ }^{5}$ OCDE 2002 (basado en precios corrientes).

\section{EL CASO ESPAÑOL}

El nivel de penetración de internet en España es más bajo de lo que puede sugerir su PIB per cápita (Guillén y Suárez, 2001). Sólo el 25,9\% de la población española accede a Internet: porcentaje que se expresa en las no muy elevadas conexiones desde el hogar, en los escasos compradores on line y en el bajo porcentaje de teletrabajadores. En el desarrollo de infraestructuras, España no destaca -en el contexto europeo- ni en el número de teléfonos, ni en la cantidad de suscriptores de banda ancha, ni en el número de ordenadores. 


\section{RIS}

En 2001, la banda ancha -que permite conexiones de mayor calidad y, se espera, a menor coste para el usuario- sólo en diez países del mundo tenía un porcentaje de suscriptores superior al $1 \%$, y entre ellos la puntera era Corea, con casi el 14\%. España ha dado un salto en los dos últimos años, con una expansión que supera los niveles de Italia y Reino Unido, y levemente los de Francia. La OCDE (2001b) considera que el cuello de botella para la generalización de la banda ancha se encuentra en las redes de acceso local, donde se combinan factores tecnológicos y de falta de competencia. Así, en Corea el elevado desarrollo en términos relativos se explica por el bajo precio de esa conexión (eEspaña, 2002), lo que nos conduce a tener en cuenta la importancia de la liberalización de las telecomunicaciones, cuyos resultados, en términos de institucionalizar una nueva modalidad de funcionamiento del mercado, operan como condicionantes de los procesos posteriores (critical juncture y path dependence). La liberalización de las telecomunicaciones empieza en España en 1998, pocos meses más tarde de lo que preveían las directivas europeas. Pese a esto, en el 2001 se abrió la competencia en las llamadas metropolitanas, y a las demoras en el proceso se sumó que la apertura del bucle local no tuvo los resultados esperados.

La Comisión Europea promovía esta apertura para abrir la competencia a otros servicios de banda ancha (como el ADSL) que de lo contrario dejarían en una situación de dominio a Telefónica (el ex monopolio). Sin embargo, en España, ante la imposibilidad de desagregar bucles, de los 17 operadores presentes en 2001 diez optaron por abandonar el mercado a fin de año por no poder lanzar sus ofertas, lo que ha aumentado los cuestionamientos a la liberalización (eEspaña, 2002). Se ha considerado que el patrón de liberalización y desregulación seguido no provocó profundas transformaciones en las reglas del juego, y mientras algunas políticas han afectado a la estructura de poder dentro del sector, se mantuvo la desigual distribución de recursos derivada de reglas informales (Jordana y Sancho, 2003). Otro análisis sugiere que el modelo seguido es de "competencia restringida", con un limitado número de operadores que han tendido a crear una estructura oligopólica de mercado, en la que Telefónica se ha ubicado en una posición dominante (Guillén y Suárez, 2001).

Por otra parte, también el gasto en $\mathrm{I}+\mathrm{D}$ tecnológico de las empresas españolas y las Administraciones públicas es bajo en comparación con el de los países del entorno europeo (en 1999 fue del 0,89 \% del PIB y en 2000 alcanzó un 0,94\%) (INE, 2002). Suecia muestra un gasto del 3,78 \% del PIB, Francia del 2,18\% y Holanda del 1,97\%.

En cuanto al diseño de políticas activas de promoción, uno de los primeros pasos fue la creación de un organismo específico. La institución gubernamental encargada de promover el desarrollo de las nuevas tecnologías, en general, y de Internet, en particular, era la Secretaría de Estado de Telecomunicaciones y para la Sociedad de la Información, dependiente (durante los gobiernos de Aznar) del Ministerio de Ciencia y Tecnología. En el año 2000, y dentro de esta Secre- 
taría, fue creada la Dirección General para el Desarrollo de la Sociedad de la Información (DGDSI), que significaba el reconocimiento formal de una unidad encargada de impulsar las políticas para la SI y la promoción de Internet. Las cuatro subdirecciones que se incluían en su seno - acceso, servicios, empresas y contenidos - señalaban las prioridades del entonces gobierno español en esta materia.

La Comisión Europea ha desempeñado un papel fundamental con la elaboración de un plan a largo plazo (eEurope, 1999) y un método abierto de coordinación entre los gobiernos nacionales, que consiste en la identificación de objetivos concretos (número de ordenadores en las aulas, seguridad en las transacciones digitales o grado de uso de Internet), para luego dejar en manos de los Estados la definición de las tareas concretas a desarrollar para alcanzar esos objetivos en sus respectivos países.

En ese contexto, el gobierno español lanzó en 1999 el ya mencionado INFO XXI (que entró en vigencia el año siguiente), un plan definido en tres síneas generales de actuación: telecomunicaciones y TIC; desarrollo de la administración electrónica, y difusión de las TIC en el conjunto de la sociedad española, tratando de "garantizar el acceso universal" (Info XXI, 2000-2003). Los primeros resultados del Plan fueron controvertidos, cuestionándose que muchas de las acciones tenían un valor testimonial más que una incidencia real, que buena parte de las partidas se destinaron a mejorar las carencias de la Administración General del Estado, y que más que una estrategia de coordinación, las iniciativas resultaron ser una suma de actividades sin el necesario nivel de integración entre los departamentos implicados en su desarrollo (Jordana et al., 2003a; eEspaña, 2002). Finalmente, el Informe conocido como "Comisión Soto" (CS, 2003), pedido por el Ministerio de Ciencia y Tecnología al percibir "que el ritmo de implantación de las nuevas tecnologías va por detrás de la evolución de las posibilidades que ofrecen las mismas" (CS, 2003: 5), destaca que entre las principales barreras a la implantación de la SI en España se pueden mencionar las siguientes: insuficiente liderazgo; limitado rigor en la concepción y ejecución de los planes ${ }^{17}$; desconocimiento de los posibles usos de las TIC; escasa capacitación; percepción desfavorable de la relación entre el valor percibido y el

\footnotetext{
${ }^{17}$ Este punto es especiamente aplicable al análisis del diseño y evolución del Info XXI. El Informe de la Comisión Soto señala: "Este aspecto, muy relacionado con una gestión deficiente, se evidencia en la ausencia de objetivos concretos y mensurables y su seguimiento limitado, lo que impide la evolución y corrección del programa a lo largo del tiempo por un lado, y el conocimiento del estado real de avance por parte de los impulsores del mismo y de los ciudadanos por el otro". Luego, agrega que otro elemento ilustrativo del estado de cosas es "la falta de coordinación generalizada que ha limitado la eficiencia, multiplicando los costes (duplicidad de esfuerzos, ausencia de intercambio de experiencias exitosas, escaso aprovechamiento de la demanda conjunta para abaratar desarrollos)". (CS, 2003: 15)
} 
coste de los equipamientos y servicios, especialmente en hogares y para grupos sociales de menor renta; ausencia de una masa crítica que dinamice el avance; y elevada complejidad asociada a la incorporación de TIC a los procesos de las instituciones públicas o privadas.

En el nivel regional, las primeras planificaciones estratégicas se desarrollaron, en 1996-97, en Murcia y Extremadura, bajo el impulso del programa RISI (Regional Information Society Initiative) de la Unión Europea. A partir de ahí, buena parte de las CC.AA han puesto en marcha sus planificaciones, y las que no lo han hecho han desarrollado actuaciones sectoriales para la modernización administrativa, la promoción de las nuevas tecnologías en la educación y la

Tabla 3.

Indicadores vinculados a la expansión de Internet por Comunidades Autónomas.

\begin{tabular}{|c|c|c|c|c|c|c|c|}
\hline \multirow{2}{*}{ Región } & \multicolumn{4}{|c|}{ Usuarios de Internet $^{1}$} & \multirow{2}{*}{$\begin{array}{c}\text { Total Gastos } \\
\text { en } \mathrm{I}^{2} \mathrm{D}^{2}\end{array}$} & \multirow{2}{*}{$\begin{array}{c}\% \text { hogares } \\
\text { con } \mathrm{PC}^{3}\end{array}$} & \multirow{2}{*}{$\begin{array}{l}\text { Renta per } \\
\text { cápita }^{4}\end{array}$} \\
\hline & 1997 & 1999 & 2001 & 2003 & & & \\
\hline Andalucía & 1,5 & 4,6 & 18,2 & 23,3 & 0,67 & 21,59 & 64,93 \\
\hline Aragón & 2,2 & 8,0 & 18,1 & 26,5 & 0,71 & 36,27 & 93,64 \\
\hline Asturias & 3,4 & 5,3 & 22,7 & 22,5 & 0,81 & 29,69 & 75,2 \\
\hline Baleares & 4,3 & 6,6 & 21,9 & 27,9 & 0,25 & 24,51 & 110,01 \\
\hline Valencia & 2,8 & 7,5 & 21,6 & 22,1 & 0,74 & 28,79 & 88,86 \\
\hline Canarias & 1,9 & 6,2 & 19,1 & 25,9 & 0,49 & 20,78 & 76,43 \\
\hline Cantabria & 1,2 & 6,1 & 19,1 & 24,6 & 0,47 & 30,11 & 80,14 \\
\hline Castilla/León & 1,6 & 4,9 & 16,0 & 21,7 & 0,64 & 27,98 & 83,04 \\
\hline Castilla/Mancha & 1,7 & 3,7 & 12,3 & 16,8 & 0,57 & 17,09 & 71,05 \\
\hline Cataluña & 4,8 & 11,5 & 26,6 & 29,4 & 1,11 & 41,72 & 107,43 \\
\hline Extremadura & 1,7 & 4,8 & 14,0 & 22,4 & 0,54 & 13,59 & 57,96 \\
\hline Galicia & 1,6 & 4,4 & 14,6 & 22,1 & 0,63 & 20,36 & 74,68 \\
\hline La Rioja & 4,0 & 7,2 & 24,3 & 16,9 & 0,61 & 34,73 & 99,84 \\
\hline Madrid & 3,9 & 9,7 & 23,4 & 32,6 & 1,67 & 51,56 & 111,48 \\
\hline Murcia & 1,7 & 6,6 & 18,5 & 22,3 & 0,74 & 15,85 & 69,57 \\
\hline Navarra & 4,0 & 5,6 & 17,3 & 22,4 & 0,92 & 33,54 & 108,32 \\
\hline País Vasco & 2,5 & 6,5 & 25,1 & 25,6 & 1,20 & 33,88 & 104,1 \\
\hline
\end{tabular}

Fuente: ${ }^{1}$ EGM; ${ }^{2}$ INE $2002 ;{ }^{3}$ eEspaña $2002 ;{ }^{4}$ Como porcentaje de la renta per cápita europea, Fundación de las Cajas de Ahorro (FUNCAS). 
promoción económica mediante del uso de las TIC. Las características de estas actuaciones varían de acuerdo a las condiciones específicas de cada región. Así, en Baleares el desarrollo está estrechamente vinculado al turismo y a los parques tecnológicos; en Extremadura, a la mejora económica en general, y en Cataluña a la promoción de las nuevas tecnologías en el conjunto de la sociedad. Con el liderazgo de las regiones más ricas, se observa, de una parte, un proceso de difusión generalizado, cuyo ritmo de crecimiento tiende a ralentizarse en los últimos dos años, y, de otra, un proceso de difusión y aprendizaje en el diseño de políticas públicas de promoción (con tendencia a asimilar las planificaciones estratégicas como principal mecanismo de intervención) (Jordana et al., 2003a).

Existe una profunda desigualdad entre las Comunidades Autónomas (tabla 3). Por ejemplo, las tres Comunidades que más destinan al $\mathrm{I}+\mathrm{D}$ en sectores relacionados con las nuevas tecnologías (como porcentaje del PIB), como son País Vasco $(1,20 \%)$, Cataluña $(1,11 \%)$ y Madrid $(1,67 \%)$, se encuentran a gran distancia de las tres que menos destinan: Baleares $(0,25 \%)$, Cantabria $(0,47 \%)$ y Castilla La Mancha $(0,57 \%)$ (INE, 2002). Aquí se repite la heterogeneidad de resultados: Baleares combina uno de los mejores indicadores en PIB per cápita (110) con bajo gasto en $\mathrm{I}+\mathrm{D}(0,25 \%)$ y alto índice de difusión de Internet $(27,9 \%)$ medido por el número de usuarios; Navarra muestra un alto PIB per cápita (108), pero su nivel de difusión de Internet está por debajo de lo esperado (22\%); en cambio las Comunidades más pobres, como Castilla La Mancha, muestran los peores niveles de penetración de Internet $(16,8 \%)$, mientras, con la excepción de Navarra, el grupo de las más ricas muestra los mejores indicadores.

Otro elemento a considerar es la velocidad de crecimiento de Internet. Aquí se puede ver que entre 1999 y 2001 se ha producido un salto en la expansión, que ha tendido a ralentizarse en el período siguiente. Así, entre 2001 y 2003, junto a Comunidades que han mantenido, aunque más lento, su nivel de crecimiento (Madrid, Cataluña, Canarias, Baleares, Extremadura, Galicia), otras se han estancado (País Vasco, Asturias, Valencia) o incluso han descendido (como es el excepcional caso de La Rioja, que ha pasado del 24,3\% en 2001 al 16,9\% en 2003).

Una vez examinadas las principales variables que intervienen en la difusión de Internet, pasamos a describir la situación a través de los indicadores seleccionados. Tal como se observa en la tabla 4, los porcentajes de difusión de Internet son bajos en todas las áreas. España tiene un porcentaje levemente superior de Pymes con presencia web que Francia, y en el resto de indicadores se ubica por encima de Portugal, con la excepción del porcentaje de usuarios y hogares conectados (cabe recordar que el nivel de riqueza español es considerablemente superior al portugués). Las columnas 2, 3 y 4 se deben leer como porcentaje sobre el total de usuarios de Internet. La información que aportan permite evaluar con mayor precisión los usos de Internet y la importancia de 
Tabla 4.

Datos de patrones de acceso y expansión de Internet

\begin{tabular}{|c|c|c|c|c|c|c|c|c|}
\hline \multirow[b]{3}{*}{ País } & \multicolumn{3}{|c|}{$\begin{array}{l}\text { Patrón de acceso } \\
\text { igualitario-desigual }\end{array}$} & \multicolumn{5}{|c|}{$\begin{array}{l}\text { Patrón de expansión } \\
\text { masivo-restringido }\end{array}$} \\
\hline & \multicolumn{2}{|c|}{ Ciudadanía } & \multirow{2}{*}{$\begin{array}{c}\text { Educación } \\
\% \\
\text { conexiones } \\
\text { centros } \\
\text { educativos }^{2}\end{array}$} & \multirow{2}{*}{$\begin{array}{c}\text { Ciudadanía } \\
\% \\
\begin{array}{c}\text { hogares } \\
\text { conectados }^{1}\end{array}\end{array}$} & \multicolumn{2}{|c|}{ Economía } & \multicolumn{2}{|c|}{ Trabajo } \\
\hline & $\begin{array}{c}\% \text { de población } \\
\text { online }^{1}\end{array}$ & $\begin{array}{c}\% \\
\text { usuarios } \\
\text { de puntos de } \\
\text { acceso público }\end{array}$ & & & $\begin{array}{l}\% \\
\text { usuarios } \\
\text { que compran } \\
\text { online } e^{*}\end{array}$ & $\begin{array}{c}\% \\
\text { Pymes con } \\
\text { presencia Web }\end{array}$ & $\begin{array}{c}\% \\
\text { teletrabajadores } \\
\end{array}$ & $\begin{array}{l}\text { Acceso en el } \\
\text { trabajo }{ }^{2 *}\end{array}$ \\
\hline España & 25,9 & 15 & 28 & 29,5 & 20,1 & $34 \%$ & 3,6 & 36 \\
\hline Suecia & 67,8 & 17 & 19 & 64,2 & 43,4 & $47 \%$ & 10,1 & 52 \\
\hline Francia & 27,9 & 12 & 23 & 35,5 & 28 & $33 \%$ & 5,6 & 45 \\
\hline Holanda & 60,8 & 10 & 18 & 65,5 & 31,4 & $48 \%$ & 9,6 & 47 \\
\hline Portugal & 50 & 8 & 27 & 30,8 & 13,2 & $14 \%$ & 2,4 & 37 \\
\hline \multicolumn{9}{|c|}{$\begin{array}{l}\text { Fuente: }{ }^{1} \text { Eurobarómetro } 2002 \text { (abril) }{ }^{2} \text { Eurobarómetro, junio } 2002 \text {. Los datos sobre lugar de conexión son citados de un estudio de eMarketer, junio } \\
\text { de 2002, }{ }^{3} \text { Eurobarómetro } 2001 \text { (noviembre); }{ }^{4} \text { Eurobarómetro } 2000 ;{ }^{5} \text { European Travel Commission, 2002. * Los datos son sobre el total de usuarios } \\
\text { de Internet. }\end{array}$} \\
\hline
\end{tabular}


los mecanismos de igualdad sobre la difusión. Por ejemplo, si en términos comparativos es muy bajo el porcentaje de usuarios de Internet y también es baja la proporción de usuarios que realizan compras on line, la deducción es que ni siquiera hay una masa de usuarios integrados capaces de retroalimentar e impulsar el proceso. Por otra parte, la importancia de las conexiones en centros educativos es destacada, lo que podría sugerir que ésta es una vía a desarrollar con la intención de profundizar en la igualdad de oportunidades de acceso. A continuación analizaremos cada una de las áreas, las principales políticas implementadas y la existencia o no de asociaciones u otros factores que puedan influir en la configuración del modelo español de difusión de Internet.

\section{La brecha digital, un problema en crecimiento}

Según datos de abril de 2002, el porcentaje de usuarios españoles de Internet $(25,9 \%)$, igual que el de hogares conectados $(29,5 \%)$ - que está muy por debajo de la media europea $(40 \%)$ - , se puede vincular con el nivel de renta (inferior al de la mayoría de los países de la UE) y con el escaso desarrollo de los indicadores de equipamientos (con 17 ordenadores personales cada 100 habitantes, frente a la media europea de 25/100), aunque en la comparación con Portugal se observa que la renta no es determinante, como mencionábamos más arriba. Por otra parte, la difusión de la telefonía móvil en España (82,42 móviles por cada 100 habitantes) (ITU, 2002), que sitúa a nuestro país en la cabecera de Europa, sugiere la necesidad de profundizar en los criterios de análisis e incorporar nociones como las sugeridas por la Comisión Soto; en este sentido, la percepción de utilidad de los ciudadanos respecto a las TIC puede ser una clave.

El gobierno español ha desarrollado políticas para estimular el crecimiento de Internet, pero no parecen haber sido suficientes para modificar el rumbo. De hecho, existen convenios de descuento para tarifas de Internet ${ }^{18}$ (políticas de promoción), acciones desarrolladas en el marco del programa Internet para todos ${ }^{19}$

\footnotetext{
${ }^{18}$ El convenio fue firmado en 1999 por el Ministerio de Fomento, estableciéndose un programa de descuentos para tarifas de acceso a Internet a través de la red de telefonía fija de Telefónica España (llamados Bononet). Por otra parte, el Real Decreto Ley 7/2000 de Medidas Urgentes en el Sector de las Telecomunicaciones establece que los operadores dominantes en el servicio telefónico fijo disponible al público deben incorporar una nueva tarifa plana para el acceso a Internet aplicable a llamadas realizadas en horario de tarifa reducida. La Asociación de Internautas (AI) surgida a partir de la demanda de una tarifa plana, consideró "un insulto a la comunidad Internet" los precios fijados (www.internautas.org)

${ }^{19}$ Internet para Todos fue una iniciativa puesta en marcha por la Asociación de Usuarios de Internet (AUI) en el año 1997. Dos años después se amplió gracias a la colaboración del Ministerio de Educación y el Centro Virtual Cervantes, y en 2002 el Ministerio de Ciencia y Tecnología, dentro
} 
o las que se prevén desarrollar en el Programa Ciudades Digitales ${ }^{20}$ (políticas de difusión).

Internet para Todos es el proyecto más destacado, con 1.100 centros abiertos y unos 5.400 usuarios (Fuente: MCyT, mayo de 2002), un porcentaje muy bajo en relación con la población total española y con objetivos muy limitados (si se le considera el proyecto estrella). Estos centros dan cursos de formación de 15 horas a un costo de 15 euros, con lo que no se ha logrado despertar el interés de los ciudadanos que no accedían a Internet ni se ha creado un espacio abierto para quienes no tienen acceso a la red en su ámbito cotidiano ${ }^{21}$. En el 2003 el millón de usuarios previstos por el programa quedó muy lejos de los 90.000 que se inscribieron. El programa cuenta con participación privada (entre sus patrocinadores destacan IBM España, Telefónica, BBVA y Microsoft) y se asienta sobre las organizaciones de la sociedad civil interesadas en albergar estos centros. Pero la ambigüedad del presupuesto, la falta de coordinación de las acciones y la falta de consenso y/o la percepción de que las decisiones se han tomado con arbitrariedad ${ }^{22}$ no han contribuido a cambiar la baja valoración de las nuevas tecnologías para los españoles (CS, 2003: 16)

Algunas Comunidades Autónomas han desarrollado políticas públicas destinadas a la creación de puntos de acceso público. Internet, dentro de las que destacan la red asturiana de telecentros ${ }^{23}$ (con 80 telecentros), el proyecto $\mathrm{Omnia}^{24}(110)$ en

del plan Info XXI, lanzó con el mismo nombre una iniciativa que compartía alguno de los objetivos planteados por la A.UI en su proyecto inicial. Internet para Todos fue presentado en enero de 2001; sin embargo, tras sucesivos lanzamientos fallidos, el programa no se inició hasta mayo de 2002.

${ }^{20}$ El Programa Ciudades Digitales aún está en su fase preliminar: a partir de acuerdos de financiación con cada Comunidad Autónoma y el Ayuntamiento en que se instale la ciudad digital, se busca desarrollar aplicaciones relacionadas con Internet, tales como administración electrónica, telemedicina, teleformación, comercio electrónico, etc. Molina de Segura (Murcia) será uno de los primeros en concretarse. Con anterioridad a este programa, se han desarrollado proyectos semejantes en Zamora, Jun y Callús.

${ }^{21}$ Un programa a realizar durante 2003-2005 y que puede ser un impulso real al acceso a Internet es el programa de Internet en las Bibliotecas, con el que se espera convertir a las 3900 bibliotecas españolas en centros donde los ciudadanos puedan utilizar las nuevas tecnologías (MCyT). Este tipo de proyectos han mostrado ser exitosos en lugares como Finlandia y Reino Unido, donde derivaron en un crecimiento importante de la penetración de Internet y en una disminución de las desigualdades (Jordana et. al., 2003b). Actualmente, sólo el $18 \%$ de las bibliotecas españolas facilita conexión a Internet, y ésta suele ser de baja calidad (El Mundo, 2-12-2002). 2003)

${ }^{22}$ Por ejemplo, adherir el sistema Microsoft frente al Linux (Cinco Días 11-07-2003 y 26-07-

${ }^{23}$ La Red Asturiana de Telecentros es una iniciativa de la Administración regional del Principado de Asturias (a través de la Dirección General de Transportes y Telecomunicaciones) y en colaboración con distintos ayuntamientos de la región. El objetivo de los telecentros es democratizar el acceso a la sociedad de la información de todos los ciudadanos, poniendo especial énfasis en la población de zonas rurales y en los grupos sociales más desfavorecidos del territorio (www.asturiastelecentros.com). 
Cataluña, y los centros Kzgunea ${ }^{25}$ (165) en el País Vasco, entre otras iniciativas. Por otra parte, algunas Comunidades también han estimulado las conexiones en hogares (como el plan Konekta Zaitez en el País Vasco, o las ayudas a las conexiones en Navarra ${ }^{26}$ ).

En cuanto a la participación de la sociedad civil, España cuenta con una Asociación de Usuarios de Internet (AUI), una entidad sin ánimo de lucro surgida en 1995 (el año de la liberalización de Internet), y que tiene el objetivo de promover el uso y conocimiento de las autopistas de la información y defender los derechos de los usuarios ${ }^{27}$. Esta asociación trabaja en colaboración con el sector público participando en sus ámbitos de discusión y diseño de las políticas, y también trabaja con el sector privado colaborando con las organizaciones empresariales. Otra institución en funcionamiento es la Asociación de Internautas (AI), que inició sus actividades en 1998 con la intención de reclamar la puesta en marcha de una tarifa plana de conexiones; actualmente brinda asesoramiento juŕídico, información y formación vinculadas a Internet.

\section{Internet en las aulas}

España supera la media europea en ordenadores conectados a Internet por 100 estudiantes y en porcentaje de escuelas con conexión a la red $^{28}$ (tabla 1). Sin

\footnotetext{
${ }^{24}$ El proyecto Òmnia se definió como una medida de prevención y lucha contra la brecha digital. En ese proyecto se han creado más de cien centros de acceso público a Internet ubicados en diferentes zonas de Catalunya y orientados al público en general o a colectivos específicos (mujeres, ancianos, inmigrantes, jóvenes, etc.) (http://www.xarxa-omnia.org). Esta iniciativa se vincula al proyecto Nodat, que reúne a la red de telecentros con el objetivo de proveer la infraestructura y los servicios necesarios para facilitar el acceso público a Internet en Cataluña.

${ }^{25}$ Los centros Kzgunea son centros gratuitos de formación y uso de Internet, orientados especialmente a los colectivos más alejados del uso de las nuevas tecnologías (ancianos, amas de casa, etc.). Se donan diversos cursos y se abre el espacio para el acceso público (http://www.kzgunea.net).

${ }^{26}$ Konekta Zaitez fue una iniciativa incluida en el Plan Euskadi para la Sociedad de la Información, con la que se buscaba facilitar el acceso a Internet de los ciudadanos haciendo asequible la adquisición de ordenadores. Concretamente se trataba de una subvención de 270,45 euros para la compra de ordenadores en los locales adheridos (http://www.konektazaitez.net). En Navarra, las facilidades para la compra de ordenadores fueron incluidas dentro del plan Navarra SI (2001-2003).

${ }^{27}$ Entre sus funciones destaca el asesoramiento a la Administración y los órganos reguladores; la AUI participa en foros y mesas de debate en la Comisión Nacional del Mercado de las Telecomunicaciones, Ministerio de Ciencia y Tecnología, Comisión de Seguimiento de los Servicios de Acceso a la Información y Comissionat per la Societat de la informació de la Generalitat de Catalunya. Asímismo, la AUI desarrolla actividades de defensa y asesoramiento de los usuarios, con una ventanilla electrónica que recoje quejas y sugerencias; y colabora con otras organizaciones nacionales e internacionales y con la Agencia de Protección de Datos, entre otros (www.aui.es).

${ }^{28} \mathrm{Al}$ observar los indicadores a lo largo del tiempo encontramos que ha habido un salto de las cifras del Eurobarómetro de marzo del 2001 a marzo del 2002, ya que mientras el porcentaje de
} 
R I S

REVISTA INTERNACIONAL DE SOCIOLOCIA

№ 37, ENERO-ABRIL, 2004

embargo, la cantidad de alumnos por ordenador - ordenadores en general, estén o no conectados a Internet- es de 33 (la media europea es de 12), siendo muy acentuadas las diferencias regionales. La Rioja o Cataluña alcanzan los 11 alumnos por ordenador, Castilla La Mancha llega a 12 y Aragón supera la media europea, con 13. En cambio, en Baleares hay un ordenador por cada 18 alumnos, en Asturias cada 19 y en Murcia cada 33. Por último, al desagregar los datos se puede observar que hay grandes diferencias en el acceso a Internet según el nivel de recursos y el tipo de escuelas. El porcentaje de alumnos que utiliza Internet en los colegios privados es del $57 \%$, mientras en los centros privados concertados baja al $32,4 \%$, y en los centros públicos al 22\% (EGM, 2002).

Las políticas públicas de promoción son intensas en el nivel regional, donde la mayoría de las CC.AA. han desarrollado acciones para crear intranets educativas, redes y contenidos digitales (Jordana et al., 2003). Desde la Administración central, la acción emblemática es el proyecto Internet en la Escuela (2001-2003) que tiene por objetivo dotar a los centros escolares de conexiones a Internet de banda ancha, de infraestructuras de redes de área local y de equipamiento multimedia para el acceso a la red. La acción se implementó por un convenio entre los Ministerios de Educación, Cultura y Deporte, y de Ciencia y Tecnología y las Administraciones educativas de las CC.AA. que han querido sumarse. Entre las críticas se ha apuntado que se tardó más de un año en efectuar la primera compra de equipos a partir de la fecha prevista, que no se establecieron los acuerdos necesarios con las Comunidades Autónomas (que tienen las competencias en el área educativa) y que no se ha afrontado uno de los principales problemas, que es la falta de formación de los profesores (Cinco Días, 11-07-2003).

Los datos recogidos a lo largo de la investigación sugieren que es necesario reformular aspectos del modelo de análisis. Así, sin estudiar la desigualdad social y regional no es posible tener una noción plena del modelo de difusión de Internet en España. Por otra parte, otros informes sugieren que también se deben tener en cuenta los usos - y no sólo los patrones de acceso y expansión. En este sentido es ilustrativo citar algunas consideraciones del citado informe de la Comisión Soto, que señala que "en contraste (con los buenos indicadores españoles en educación), las escuelas no han desarrollado el potencial de estas infraestructuras al mismo nivel que el resto de los países, ya que el número de escuelas que disponen, por ejemplo, de intranet es inferior a la media (37\% frente al 53\% de media en Europa). Igualmente, la disponibilidad de conexión no refleja el uso que los alumnos hacen de los ordenadores PC para conectarse a Internet. Mientras en la UE se utilizan los ordenadores conectados a Internet una media de 0,7 horas por semana, en España el tiempo dedicado es de 0,4 horas" (CS, 2003: 14).

escuelas conectadas se mantiene en el $94 \%$ (mientras la media europea pasaba del $89 \%$ al $93 \%$ ) el porcentaje de ordenadorers conectados por cada 100 alumnos pasa de 3,3 a 6,4 . 


\section{Empresas y consumidores en red}

El X Informe de la Comisión del Mercado de las Telecomunicaciones (CMT), de diciembre del 2002, se centra en evaluar el comercio electrónico español a partir de entidades de medios de pago; es decir, considera los productos o servicios contratados por los usuarios españoles a través de Internet y que se realizan mediante tarjetas de crédito. Esto significa que dicho informe sólo se centra en las transacciones realizadas mediante tarjetas de crédito (un 53,7\%) (del resto de las transacciones, el $29,1 \%$ se paga mediante reembolso y el porcentaje restante mediante transferencia bancaria $u$ otras fórmulas). Se incluyen las transacciones de residentes en España que utilizan un medio de pago español y las de no residentes con sitios comerciales españoles.

La primera observación indica que, en consonancia con los bajos niveles de penetración de Internet, España está por debajo de la media de la UE. Los datos señalan un crecimiento importante en términos absolutos, aunque continúe la distancia con la media europea en términos relativos. Un estudio de la consultora TN Sofres sobre 37 países, señala que España tiene un 10\% de compradores activos (sobre el total de usuarios de Internet), cinco puntos por debajo de la media del estudio. Por otra parte, el uso de Internet se limita a la búsqueda de información, y sólo un $14 \%$ de los usuarios realizan compras de productos o servicios frente

Tabla 5.

Comercio electrónico mediante medios de pago en España (2001-2002).

\begin{tabular}{|c|c|c|c|c|c|c|c|c|}
\hline \multirow[b]{2}{*}{$\begin{array}{l}\text { Tipo de } \\
\text { transacción }\end{array}$} & \multicolumn{4}{|c|}{ Año 2001} & \multicolumn{4}{|c|}{ Año 2002} \\
\hline & $\begin{array}{l}\text { Número } \\
\text { de } \\
\text { operaciones }\end{array}$ & $\begin{array}{c}\% \\
\text { sobre } \\
\text { el total }\end{array}$ & $\begin{array}{l}\text { Miles } \\
\text { de } \\
\text { euros }\end{array}$ & $\begin{array}{c}\% \\
\text { sobre } \\
\text { el total }\end{array}$ & $\begin{array}{c}\text { Número } \\
\text { de } \\
\text { operaciones }\end{array}$ & $\begin{array}{c}\% \\
\text { sobre } \\
\text { el total }\end{array}$ & $\begin{array}{l}\text { Miles } \\
\text { de } \\
\text { euros }\end{array}$ & $\begin{array}{c}\% \\
\text { sobre } \\
\text { el total }\end{array}$ \\
\hline $\begin{array}{l}\text { Transacciones } \\
\text { españolas } \\
\text { en el exterior }\end{array}$ & 961.087 & $41 \%$ & 58.151 & $46 \%$ & 2.154 .113 & $52 \%$ & 122.670 & $53 \%$ \\
\hline $\begin{array}{l}\text { Transacciones } \\
\text { del exterior } \\
\text { en España }\end{array}$ & 202.366 & $9 \%$ & 22.560 & $18 \%$ & 342.817 & $8 \%$ & 37.540 & $16 \%$ \\
\hline $\begin{array}{l}\text { Transacciones } \\
\text { en España }\end{array}$ & 1.204 .439 & $51 \%$ & 46.382 & $6 \%$ & 1.648 .077 & $40 \%$ & 73.371 & $31 \%$ \\
\hline
\end{tabular}

Fuente: CMT, octubre-diciembre 2002. 


\section{RIS}

al 35\% de media europea. Pese a esto, en términos absolutos, el crecimiento del mercado es considerable ${ }^{29}$.

El porcentaje de Pymes con presencia en la web (34\%) es semejante al de Francia (33\%) y superior al de Portugal (14\%). En cuanto a las políticas públicas de promoción desde la Administración central, el proyecto emblemático es ArtePyme (2001-2006). En el marco de este programa se conceden ayudas a los proyectos basados en el comercio electrónico de servicios avanzados de telecomunicación (SAT) para las pequeñas y medianas empresas; asimismo, promueve el desarrollo de redes para el intercambio de conocimientos y una mayor capacitación para poner en el mercado sus productos a través de medios informáticos y telemáticos ${ }^{30}$. También hay diversos programas en los niveles regionales, donde nuevamente se manifiestan los desequilibrios territoriales que ArtePyme en este caso intenta paliar, ya que se destaca que al menos el $70 \%$ de las Pymes favorecidas deberá ubicarse en las regiones del objetivo 1 (regiones desfavorecidas en las que los fondos FEDER financian iniciativas de reactivación).

La Asociación Española de Comercio Electrónico (AECE) inició sus actuaciones en este ámbito en 1998, promovida por la Federación de Comercio Electrónico y Marketing Directo (fundada en 1977). Los objetivos de la AECE son fomentar el comercio electrónico en España y defender los intereses de las empresas españolas en esta materia; actuar ante los organismos europeos y la Administración española para lograr una legislación favorable para el sector; y "propiciar los mecanismos necesarios para que la autorregulación sea una realidad sobre la que las empresas españolas puedan desarrollar sus actividades comerciales en la red con plena seguridad" (www.aece.org).

Según diversos estudios, las razones que pueden explicar el atraso del comercio on line en el mercado español son la desconfianza de los consumidores ${ }^{31}$, la falta

\footnotetext{
${ }^{29}$ Las transacciones con origen en España y dirigidas al exterior crecieron un 109\% en el número de operaciones y un $106 \%$ en el volumen económico; las transacciones realizadas desde el exterior en España crecieron un $67 \%$ y un $40 \%$ en volumen económico, y en las operaciones con origen y destino en España hubo un incremento del 40,5\% en número y del 101,6\% en volumen económico (publicado en www.aece.org).

${ }^{30}$ Podrán ser beneficiarias de este Proyecto las organizaciones públicas o privadas que, sin ánimo de lucro, tengan la finalidad de prestar servicios de apoyo a las pequeñas y medianas empresas, mediante la realización de proyectos comunes de asistencia o la promoción de servicios que contribuyan a la promoción y mejora de la competitividad de las Pymes. Se gestiona por la Secretaría de Estado de Telecomunicaciones y para la Sociedad de la Información y está cofinanciado por el Fondo Europeo de Desarrollo Regional (FEDER). Sus líneas de actuación son: estudio de necesidades y viabilidad, proyectos piloto, implantación y promoción de SAT (Servicios avanzados de Telecomunicaciones).

${ }^{31}$ Un estudio de la Fundación Grupo Eroski (publicado en Consumer.es) traza una de las líneas explicativas del desinterés de los españoles por las transacciones electrónicas. La investigación se
} 
de seguridad en las transacciones electrónicas y la baja penetración de las nuevas tecnologías, especialmente en las PYMES ${ }^{32}$.

\section{Internet en el trabajo y el trabajo por Internet}

En el ámbito del teletrabajo encontramos, junto con los bajos niveles de desarrollo, la existencia de distintas políticas de promoción tanto desde el nivel europeo, como desde el nivel regional. Los trabajos asociados a las nuevas tecnologías han sido los primeros en adoptar esta modalidad. Entre ellos destacan las consultorías y el diseño de páginas web. Hay nuevas áreas, como las ventas on line en formato digital y la actividad de la enseñanza, mientras otros empleos permiten la alternancia entre el trabajo en la oficina y en el hogar, que es una tendencia ascendente en muchos países.

En España, la utilización de Internet en el trabajo es baja, lo cual es"coherente con la baja penetración de Internet en las empresas. Así, por una parte, la proporción de trabajadores que se conectan desde el lugar de empleo es inferior a la de la mayoría de los países de la UE, con excepción de Portugal (lo que es más relevante si consideramos que estos porcentajes se desagregan del total de población conectada, que en España es muy inferior a la del resto de los países seleccionados). A pesar del impulso que se le ha dado desde la Unión Europea, el teletrabajo no ha tenido éxito en España. Esta tendencia se explica, en primer lugar, por el bajo desarrollo de las TIC en el mercado español, y, en segundo lugar, como algunas encuestas señalan, por la falta de confianza de los empresarios (que prefieren mantener el control sobre los trabajadores), por el miedo de los trabajadores a tener que asumir los costes (gastos de electricidad, conexión y ordenador) y por el miedo a precarizar su situación laboral ${ }^{33}$ (El Mundo, 6-10-2002).

\footnotetext{
realizó sobre 20 comercios on line en los que se hizo el seguimiento de compra de CD's, el principal producto en las transacciones electrónicas. Se detectaron problemas tales como incumplimiento de la legislación vigente, demoras en las entregas y diferencias entre el producto ofrecido y el entregado al consumidor. En este marco se entiende que los consumidores afirmen no comprar en red por falta de información, miedo a facilitar los datos personales y desconfianza en el sistema de pago.

${ }^{32}$ Según el Estudio sobre las Barreras Sectoriales para la Venta Electrónica (de las Cámaras de Comercio), el $70 \%$ de las empresas españolas considera que la reticencia de los consumidores es el principal freno al desarrollo del comercio electrónico. Frente a esto, la media de las empresas europeas muestra como principal obstáculo la imposibilidad de vender algunos bienes y servicios por Internet (Cinco Días, 7-08-2003). Otro estudio realizado por la Confederación General de Pequeñas y Medianas Empresas (Copyme) señala que el 36,3\% de las pequeñas y medianas empresas españolas no emplea en su trabajo diario ni Internet ni el correo electrónico (Cinco Días, 16-07-2003).

${ }^{33}$ Algunos estudios han asociado, en España, las nuevas formas de empleo con la precarización laboral. El modelo de flexibilización laboral ha promovido la temporalidad y la dependencia familiar sin resolver el problema del desempleo con el que se legitimó la reforma (Ramos-Díaz 2003).
} 
RIS

REVISTA INTERNACIONAL DE SOCIOLOGIA

№37, ENERO-ABRIL, 2004

YANINA WELP

Uno de los apartados del Informe eWork 2001, que muestra la situación del teletrabajo Europa, señala para España el hecho de que el e-trabajo está viviendo un "segundo florecimiento" a través de la concienciación creciente de los ciudadanos, señalando además que "la demanda pública forzará a las empresas y administraciones a adoptar una estructura organizativa diferente". Esta concienciación ciudadana se encuentra reflejada en decenas de iniciativas regionales y locales impulsadas y reforzadas por redes de ciudadanos. Por su parte, la Administración central se ha limitado a organizar reuniones con expertos en la materia y solicitar estudios o informes (DeTeletrabajo.com N ${ }^{\circ}$ 64, 2002).

$\mathrm{Al}$ igual que en otras áreas, existe una organización dedicada al tema, la Asociación Española de Teletrabajo (AET). La AET es una organización sin ánimo de lucro que tiene como objetivo primordial la promoción e implantación del teletrabajo. Surge en 1994 y tiene existencia en la red desde 1995. La AET propugna y promociona el uso de la red y las nuevas tecnologías para una reorganización laboral paralela a los cambios empresariales. La idea de sus miembros es ofrecer soluciones complejas a las empresas y defender al mismo tiempo el margen de negociación de los trabajadores, convirtiendo una posición débil de "demandante individual de formación y de empleo" en otra posición más fuerte de "grupo creador de conceptos que ofrezca soluciones". Con estas ideas, la AET realiza encuestas para las empresas, participa en distintos foros y realiza propuestas a la Administración central.

\section{CONCLUSIONES}

Las conclusiones extraídas de la presente investigación apuntan en dos sentidos: por un lado, caracterizar la difusión de Internet en España; por otro, evaluar el modelo de análisis y sugerir reformulaciones y futuros desarrollos del mismo.

En cuanto al primer objetivo, los datos permiten afirmar que el modelo español de difusión de Internet es restringido en cuanto a su patrón de expansión (ya que en casi todas las áreas muestra bajos niveles) y relativamente desigual en el patrón de acceso (ya que los usuarios que no disponen de conexiones en sus hogares tampoco cuentan con una infraestructura suficiente para hacerlo en el ámbito público, lo que debería analizarse con más detalles para el caso del sector educativo). Sin embargo, la fuerte intervención pública en el área nos obliga a plantear la necesidad de profundizar en el diseño del modelo de análisis y/o reformularlo de cara a futuras investigaciones.

El bajo nivel de desarrollo económico no es una explicación suficiente, tal como han señalado Guillén y Suárez (2001), que consideran que, según su PBI, el nivel de penetración de Internet debería ser superior en España (tal como podría esperarse si se observa la amplia difusión de la telefonía móvil). Estos autores, y también Hargittai (1999), han observado la importancia de la situación de mercado 
para estimular la penetración de Internet. En este sentido, la liberalización de las comunicaciones puede entenderse como una critical juncture (Collier y Collier, 2002) que ha dejado su herencia. Más aun, la situación de competencia restringida y el reforzamiento de los recursos informales de poder (Jordana y Sancho, 2003) pueden entenderse como la pervivencia de una forma de organización del mercado de las telecomunicaciones que no contribuye a estimular la expansión de Internet: menos competencia y restricciones a la misma implican menos promoción y mayores costes de acceso.

En cuanto a las políticas públicas, hemos visto que la planificación ha sido intensa tanto en el nivel del gobierno central como en el regional, lo que debe llevarnos a considerar su falta de eficiencia (el decoupling o desajuste entre la propuesta formal y el funcionamiento efectivo), ya que los resultados de estas políticas no han cumplido las expectativas, lo que el mismo gobierno central ha admitido al evaluar el Info XXI (tal como señala el mencionado informe de la Comisión Soto). El isomorfismo institucional puede verse en la tendencia a la planificación vertical y centralizada, que se ha continuado haciendo mientras que en otros países europeos se demostraba la importancia de generar consensos para el desarrollo de áreas vinculadas a Internet (Jordana et al., 2003b). Esto es un problema, a pesar de la tendencia a la intervención de las empresas en programas como Internet para todos, y de la existencia de instituciones representativas de grupos de interés tanto de los usuarios como de las empresas que practican el comercio electrónico y de los promotores del trabajo a distancia.

Por otra parte, cabe señalar que no ha habido un estímulo decidido y eficaz hacia la creación de redes de telecentros o puntos de acceso público que permitan que los ciudadanos accedan a Internet con independencia de su nivel de renta. $Y$ si bien encontramos políticas públicas de promoción, difusión y regulación, éstas no han sido capaces todavía de crear una demanda ni un marco apropiado para el desarrollo de Internet. La situación en las Comunidades Autónomas es desigual, con algunas Comunidades punteras, como Madrid, Cataluña o País Vasco, en las que el desarrollo económico y el diseño de políticas mejoran los resultados de las acciones llevadas a cabo por la Administración central. En cuanto a la débil coordinación entre ambos niveles, parece ser otro path dependence, tal como se ha visto en los problemas generados para la aplicación del programa Internet en la Escuela.

En el impulso del comercio electrónico y el teletrabajo, los primeros estudios sobre el tema muestran que la desconfianza de los empleadores, los trabajadores y los consumidores, a lo que se une el círculo vicioso de la mala calidad de los servicios de algunas empresas españolas (detectadas en investigaciones como la de eConsumer), aparecen como las primeras fuentes de explicación. La desconfianza en la regulación y la sensación de desamparo de consumidores y trabajadores pueden reforzar esta tendencia. Por otra parte, la existencia de instituciones sin ánimo de lucro que representen intereses de estos sectores podría ser una estrategia 
RIS

REVISTA INTERNACIONAL DE SOCIOLOCIA

No 37, ENERO-ABRIL, 2004

YANINA WELP

para mejorar la interrelación entre el sector público y el sector privado, aunque de momento esto no ha mostrado efectos relevantes sobre el diseño de las políticas públicas.

\section{Consideraciones sobre el modelo de análisis}

Como aspectos positivos, el modelo propuesto ha permitido analizar el caso español teniendo en cuenta la influencia de distintas variables, lo que permite concebir la difusión de Internet como un proceso complejo y multidimensional. El neoinstitucionalismo ha mostrado tener un gran valor como herramienta de investigación, ya que llama la atención sobre aspectos relevantes para comprender los malos resultados de las políticas públicas en la promoción de Internet. En esta línea, las hipótesis señaladas deberían ser reformuladas para medir también la eficiencia-ineficiencia de las políticas públicas. Así, según nuestro modelo, mientras las variables explicativas deberían llevarnos a situar la difusión de Internet en España como igualitaria y restringida, los resultados ubican al país en el cuadrante desigual-restringido.

El neoinstitucionalismo puede permitirnos comprender el efecto de las presiones de la UE y su conjugación con la path dependence como factores relevantes para mejorar y ajustar el modelo, y entender por qué, habiendo una planificación intensa, los resultados han sido negativos. También debería profundizarse en el análisis de las políticas públicas, en el que nuestra aproximación sugiere que a pesar de ser una nueva área de actuación se ha encontrado fuertemente influida por patrones de actuación preexistente: por ejemplo, verticalismo, descoordinación entre sectores y falta de rigurosidad en el diseño de políticas (como el Info $\mathrm{XXI}$, en el que numerosas acciones no tienen fijado ni presupuesto, ni período de desarrollo, ni responsable).

Por otra parte, algunas reflexiones que deberían ser contrastadas con estudios posteriores sugieren que en España la brecha digital puede ser amplia entre quienes acceden y quienes no, tanto entre regiones como entre sectores socioeconómicos. La importancia relativa de las conexiones en centros educativos y la del acceso en cybercafés debería ser contrastada con estudios posteriores que permitan profundizar en el perfil de los usuarios. Podemos anticipar que según información de la AIMC los usuarios son mayoritariamente jóvenes y vinculados al sector educativo, y estos análisis permitirían comprobar si estamos o no ante un proceso de ampliación de las desigualdades en el que los estudiantes de centros privados tienen posibilidades de acceso muy superiores a los estudiantes de escuelas públicas (como mencionábamos, el $57 \%$ de los alumnos de escuelas privadas utiliza Internet, frente al $22 \%$ de los estudiantes de centros públicos, y esto sin considerar la calidad de las conexiones). Por otra parte, el mismo estudio muestra una pronunciada desigualdad en el acceso según nivel de ingresos, de lo que se puede inferir que muchos estudiantes de centros privados pueden ser quienes cuentan con 
conexiones en sus hogares y cuyos padres se conectan desde el trabajo. En todo caso, las limitaciones del estudio exigen que, para mejorar nuestra comprensión del tema, debería analizarse el perfil de los usuarios, utilizando microdatos que permitan hacer un análisis exhaustivo.

\section{REFERENCIAS BIBLIOGRÁFICAS}

ABBATE, J. (1999), Inventig the Internet, Cambridge, MIT Press.

BACCHETTA, M. et al., (1998), El comercio electrónico y el papel de la OMC, Ginebra, OMC.

BELL, D. (1994[1973]), El advenimiento de la sociedad post-industrial, Barcelona, Alianza.

BERNERS-LEE, T. y M. FISCHETTI (1999), Weaving the web. The original design and ultimaty destiny of the world wide web by its inventor, San Francisco, Harper.

BRADFORD DE LONG (1998), "How “New' Is Today's Economy?”, www.j-bradford-delong.net Comments/How_New.html.

CAIRO CAROU, H. (comp.) (2002), Democracia Digital. Limites y oportunidades, Madrid, Trotta.

CASTELLS, M. y P. HIMANEN (2002), El estado del bienestar y la sociedad de la información. El modelo finlandés, Madrid, Alianza editorial.

CASTELLS, M. (1997), La era de la Información, Madrid, Alianza.

(2001), La Galaxia Internet, Barcelona, Plaza \& Janés.

CIDEC (2003), Informe de resultados 1: Panorama general del teletrabajo, España, CIDEC.

COLLIER, R. y D. COLLIER (2002), Shaping the political arena. Notre Dame, Indiana, University of Notre Dame Press.

COMISIÓN EUROPEA (2000), e-Learning. Concebir la educación del futuro, Bruselas, Comisión Europea.

COMISIÓN SOTO (2003), Aprovechar la oportunidad de la sociedad de la información en España, Recomendaciones de la Comisión Especial de Estudio para el Desarrollo de la Sociedad de la Información, Madrid, 1 de abril.

COMPAINE, B. (2001), The Digital Divide: facing a crisis or creating a myth, Cambridge MIT Press.

DODGE, M. y R. KITCHIN (2001), Mapping Cyberspace, Nueva York, Routledge.

DRAKE, W. (1993), “The Internet religious war”, Telecommunications Policy, no 17 (9), pp. 643-648. 
RIS

REVISTA INTERNACIONAL DE SOCIOLOGIA

№ 37, ENERO-ABRIL, 2004

DUTTON, W. H. (Ed.). (1996), Information and Communication Technologies, Oxford, Oxford University Press.

(1999), Society on the Line, Oxford, Oxford University Press.

FREEMAN, C. (1996), The two edged nature of technological change: employment and unemployment, en W. Dutton (ed), Information and Communication Technologies, Oxford, Oxford University Press.

GELL, M. y P. COCHRANE (1996), Learning and Education in an Information Society, en H. Dutton, (ed.), Information and Communication Technologies, Oxford, Oxford University Press.

GIBBS, J., K. KRAEMER y J. DEDRICK (2003), "Environment and Policy factors shaping global eCommerce difusión: a cross country comparison", The Information Society, $\mathrm{n}^{\circ}$ 19, pp. 5-18.

GUILLÉN y SUÁREZ (2001), "Developing the Internet: entrepreneurship and public policy in Ireland, Singapore, Argentina and Spain", Telecommunications Policy, $\mathrm{n}^{\circ} 25$ (5), pp. 349-371.

HAMMER, M. y J. CHAMPY (1994), Reingeniería de la empresa, Barcelona, Parrramón.

HARGITTAI, E. (1999), "Weaving the Western Web: explaining differences in Internet connectivity among OECD countries", Telecommunications Policy, n² 23, pp. 701-718.

HART, J., R. REED y F. BAR (1992), "The building of the Internet. Implications for the future of broadband networks", Telecommunications Policy, $\mathrm{n}^{\circ} 16$, pp. 666-689.

HUWKS, U. (1993), "Teleworking in Britain. A report to the Employment Department", Analytica Research Series, $\mathrm{n}^{\circ} 18$.

IBÁÑEZ MUÑOZ, J. (2002), El control del comercio electrónico en Internet (Tesis Doctoral), Universidad Pompeu Fabra.

IMMERGUT, E. (1998), "The theoretical core of the New Institutionalism", Politics and Society, vol. $26, \mathrm{n}^{\circ} 1$, pp. $5-34$

(1992), Health Politics. Interests and Institutions in Western Europe, Cambridge, Cambridge University Press.

JORDANA, J. (2001), "Desigualtats digitals i societat de la ifnormació: un debat pendet", Papers de la Fundació, n¹30, Fundació Rafael Campalans.

JORDANA, J., D. SANCHO, X. FERNÁNDEZ, Y. WELP y I. PUIG (2003a), Planificant la Societat de la Informació. Una anàlisi de les iniciatives impulsades per les administracions públiques a Espanya, Barcelona, DURSI.

JORDANA, J., D. SANCHO y Y. WELP (2003b), "Les polítiques públiques de promoció i difusió de la Societat de la Informació a Europa", Coneixement I Societat, $\mathrm{n}^{\circ} 3$.

JORDANA, J. y D. SANCHO (2003), "Policy Networks and the opening up of the market: the case 
of telecommunication liberalization in Spain", Estudio Working Paper 2003/188, Instituto Juan March de Estudios e Investigaciones.

LESSIG, L.(2001), El código y otras leyes del ciberespacio, Madrid, Taurus.

LYON, D. (1988), The Information Society. Issues and illusions, Cambridge, Polity Press.

MACHLUP, F. (1987), "Knowledge production and occupational structure", en A. Cawkell (ed.), Evolution of an information society, Londres, Aslib.

MACIÀ, S. (1999), "El tímido proceso de definición del servicio universal de las telecomunicaciones en España", en J. Jordana y D. Sancho (eds.), Politicas de Telecomunicaciones en España, Barcelona, Tecnos.

MALAMUD, C. (1993), Exploring the Internet. A technical travelogue, Prentice Hall, Englewood Cliffs.

MARSDEN, C. (ed.) (2000), Regulating the global information society, Londres y Nueva York, Routledge.

MASUDA, Y. (1981), The Information Society, Washington, World Future Society.

MEYER, J. y B. ROWAN (1991), "Institutionalized organizations: formal structure as myth and ceremony", En Powell y DiMaggio, The New Institutionalism in Organizational Analysis, Chicago y Londres, University of Chicago Press.

MILES, I. (1996), "The Information Society: Competing perspectives on the social and economic implications of information and communication technologies", en W. Dutton (ed.), Information and Communication Technologies, Oxford, Oxford University Press.

MILNER, H. (2002), "The global spread of the Internet: the role of international diffusion pressures in technology adoption", presentada en Yale University en mayo 10-11.

NEGROPONTE, N. (1995), Being Digital, Londres, Hodder and Stoughtton.

NORRIS, P. (2000), "The Worldwide Digital Divide", Paper for the Annaul Meeting of the Political Studies Association of the UK, London School of Economics and Political Science, 10-13 abril.

OCDE (1999), The Digital Economy, París, OCDE.

(2001a), Understanding the digital divide, París, OCDE.

(2001b), The development of broadband access in OECD countries, París, OCDE.

(2002), Measuring the Information Econmy, París, OCDE.

PÉREZ DE LOS COBOS, F. y J. THIBAULT ARANDA (2001), El teletrabajo en España, Madrid, Ministerio de trabajo y Asuntos Sociales. 
PETERS, G. (2003), El nuevo Institucionalismo, Barcelona, Gedisa.

PIERSON, P. (1993), "When effects, becomes cause: policy feedback and political change”, World Politics, vol. 45 (4), pp. 595-628.

(2000), "Increasing returns, Path Dependence and the Study of Politics", American Political Science Review, $\mathrm{n}^{\circ}$ 94, pp. 251-268.

POWELL, W. y P. DIMAGGIO (1991), The New Institutionalism in Organizational Analysis, Chicago y Londres, University of Chicago Press.

PROENZA, F. (2002), "e-Para Todos: Una estrategia para la reducción de la pobreza en la era de la información”, www.educoas.org/portal/docs.e-paratodos.pdf, también se puede encontrar en www.aat-ar.org/documentos/e-paratodos

(2002), "Telecenter sustainability. Myths and opportunities", Jornal of Development Communication, November.

RAMOS DÍAZ, J. (2003), ¿Son compatibles altos niveles de flexibilidad laboral y altos niveles de protección social?, Fundacio Campalans, Barcelona.

RIFKIN, J. (1996), The end of Work, Nueva York, G.P.Putnam's sons.

SAMUELSON, P. (2000), "Five Challenges for regulatin the Global Information Society", en Marsden, Ch. (ed.), Regulating the global information society, Londres y Nueva York, Routledge.

SLOUKA, M. (1996), War of the worlds: cyberspace, the high tech assault on reality, Londres, Abacus.

TAYLOR, J., C. BELLAMY, C. RAAB, W. DUTTON y M. PELTU (1996), "Innovation in Public Service Delivery", en H. Dutton (ed.), Information and Communication Technologies, Oxford, Oxford University Press.

THATCHER, M. (2000), Cross-nationa linkages and regulatory reform in Europe: te case of telecommunications, Presentado en el Annual Meeting of the American Political Science.

TELEFÓNICA (2002), La sociedad de la información en España, Madrid, Telefónica.

TOFLER, A. (1990), La tercera ola. Barcelona, Plaza \& Janés.

TOURAINE, A. (1971), La sociedad post industrial, Barcelona, Ariel.

WERLE, R.(2001), "Internet @ Europe: Overcoming institutional fragmentation and policy failure", en http://eiop.or.at/eiop/texte/2001-007a.htm.

WIENNER, N. (1989), The human use of human beings cybernetic and society, Londres, London Free Association Books.

WOLCOTT, M. y S. GOODMAN (2003), "Introducing the global diffusion of the Internet series", Association for Information Systems, vol. 11, pp. 555-559. 
WOLCOTT, P., L. PRESS, W. MCHENRY, S. GOODMAN y W. FOSTER (2001), “A framework for assesing the global difusión of the Internet", Association for Information Systems, vol. 2, artículo 6 .

\section{ENLACES Y RECURSOS ESTADÍSTICOS}

\section{España}

AECE: Asociación Española de Comercio Electrónico (http://www.aece.org)

AET: Asociación Española de Teletrabajo (2001). e-Trabajo 2001. Informe de la situación de Nuevos Modos de trabajar en la Economía del Conocimiento, traducción al castellano con comentarios del Informe de la Comisión Europea (http://www.aet-es.org)

AIMC: Asociación para la Investigación de Medios de Comunicación (http://www.aimc.es)

AUI: Asociación de Usuarios de Internet en España (http://www.aui.es)

CMT: Comisión del Mercado de las Telecomunicaciones (www.cmt.es)

MCyT: Ministerio de Ciencia y Tecnología (http://www.mcyt.es)

INE: Instituto Nacional de Estadística (www.ine.es) Info XXI (http://www.infoxxi.es)

\section{Europa}

eEUROPE (http://europa.eu.int/information_society/eeurope/index_en.htm)

SIBIS. Statistical Indicators Benchmarking the Information Society, (http://www.empirica.biz/ sibis/)

EUROPEAN TRAVEL COMMISSION: (http://www.etcnewmedia.com)

EUROSTAT: (http://europa.eu.int/comm/eurostat/)

EUROPAMEDIA: (http://www.europemedia.net/)

\section{Otros}

COMSCORE: (http://www.comscore.com/)

CONSUMER.ES (Diario del Consumidor) (http://www.consumer.es)

eMARKETER: (http://www.emarketer.com/)

FORRESTER: (http://www.forrester.com/home/0,6092,1-0,FF.html)

GARTNER: (http://www4.gartner.com/Init) 
R I S

REVISTA INTERNACIONAL DE SOCIOLOGIA

№ 37, ENER0-ABRIL, 2004

YANINA WELP

GLOBAL REACH (2002 y 2003) (http://www.glreach.com/globstats)

UNESCO: (http://www.unesco.org/webworld/observatory/index.shtml)

ITU: International Telecommunication Union (http://www.itu.int)

NIELSEN NET RANKINGS: (http://www.nielsen-netratings.com/)

NUA INTERNET SURVEYS: (http://www.nua.com/surveys/L

WORLD PAPER (2002) ISI (www.worldpaper.com/indexes/ISI/012002/TheWorldPaperISI200 .pdf) 